\title{
Mortgage Asymmetric Pricing, Cash Rate and Foreign Funding Cost: Australian Evidence
}

\begin{abstract}
This study investigates asymmetry in the interest-rate pass-through at the bank level in Australia over the period 2002:7-2015:12 in a distinctive manner. First, we examine the transmission of the foreign-funds rate, in parallel with the cash rate, to bank mortgage rates. Second, we utilize the Nonlinear Auto-Regressive Distributed Lag (NARDL) framework of Shin et al. (2014) in panel form to capture both the time-variation and cross-section variation within bank groups. Third, we simultaneously explore heterogeneous asymmetry in the passthrough for funding cost increases and decreases on impact, in the short term and in the long term. Our results reaffirm the asymmetric relationship between the cash rate and mortgage rates. We validate that international funding costs do indeed asymmetrically drive mortgage rates. The heterogeneous asymmetry in interest-rate pass-through found in both full- and subsample analyses signifies that market pricing power exists in which the major banks are the most powerful in mortgage pricing, while the smaller lenders are price-takers. These findings provide important implications for policy makers, investors, and the public.
\end{abstract}

Keywords: Asymmetry, Interest-rate Pass-through, Mortgages, International funding cost, Cash rate, Panel NARDL.

JEL Classifications: G21, E43, E58 


\section{Introduction}

Mortgage rate movement is an important issue because it has significant implications for the economy, consumers and the effectiveness of monetary policy. Mortgage rates affect the housing market, which has been shown to be an important sector of the economy (Elbourne, 2008; Musso, Neri, \& Stracca, 2011). Mortgage rate movements ultimately influence the value of houses, and this can affect consumption through the so-called "wealth effect". ${ }^{1}$ Mortgage rates play an important role in the interest rate channel for monetary policy transmission (Calza \& Stracca, 2013).

Mortgage rate movement is a fiercely debated issue in Australia.

- Australia is a nation of home-loan borrowers. The largest component of Australian household debt is home loans, accounting for $91.8 \%$ of the total (Reserve Bank of Australia [RBA], 2017). This borrowing has created a huge residential market which, at the end of October 2016, was valued at AU\$6.7 trillion (Lawless, 2016), making it four times larger than the listed equity market value of AU\$1.664 trillion. ${ }^{2}$ This large property market value has made Australians the richest in the developed world (Commins, 2014).

- Most Australian bank loans are on mortgages. Data from the Reserve Bank of Australia (RBA) showed that housing loans accounted for $59.35 \%$, while borrowings for commercial and other purposes represented $36.61 \%$ and $4.04 \%$ of total loans, respectively (RBA, 2017). As shown in Figure 1, Australian banks have the highest proportion of residential loans in the world.

\section{[Insert Figure 1 here]}

- As with the UK, the EU, and Canada, $85 \%$ of total home loans in Australia are at variable rates (Australian Bureau of Statistics [ABS], 2017 "Tables 9-1a"). This variation is in contrast to the US, where about $93 \%$ of home loans since 2009 have been fixed rate mortgages (Fuster \& Vickery, 2015).

Hence, the movement of mortgage interest rates in Australia is of utmost importance: also, it is a very sensitive public issue that has involved politicians, the media, and the general public.

\footnotetext{
${ }^{1}$ Whenever the value of their properties increase (decrease), consumers feel wealthier (poorer); hence, this causes them to increase (decrease) their consumption (Campbell \& Cocco, 2007; Navarro \& de Frutos, 2015; Peltonen et al., 2012)

${ }^{2} \mathrm{http}: / /$ www.asx.com.au/about/historical-market-statistics.htm\# End_of_month_values
} 
Mortgage interest rates are driven by numerous factors. One key factor that is closely monitored in Australia is the impact of the cash rate (the policy rate) on mortgage rates. Historically, the Australian public has expected that mortgage rates would closely follow the movement of the cash rate. However, in recent years, the two have noticeably diverged. Banks have been passing on more substantial increases in the cash rate to mortgage holders, but have not done so in the case of decreases in the cash rate - thus creating an asymmetric relationship between the cash rate and mortgage rates. For example, the cash rate on 2nd August 2016 dropped by $0.25 \%$ from $1.75 \%$ to $1.5 \%$. However, most mortgage borrowers received only half of this reduction. The four biggest banks in Australia, which control around $85 \%$ of total mortgages, ${ }^{3}$ decreased their standard variable rates by only 10,12,13 and 14 basis points (bp) respectively, equating to only about half of the 25 basis-point reductions in the cash rate.

This asymmetric response of mortgage rate to cash rate has resulted in an outcry from the general public, the media and politicians. Media commentators have focused their attack on why lenders are too slow to reduce their retail rates (Long, Sales, \& Puccini, 2011) and why they pass on only partial rate cuts to their mortgage borrowers (Janda, 2016). The Prime Minister of Australia even joined the chorus of anger by asking banks to provide the public with explanations for this asymmetry (McIlroy, 2016). The opposition (Labor) party has even proposed setting up a very powerful commission (Royal Commission) to investigate this bank behavior if they win government in the next election (Farr, 2016).

Banks counter these protests, saying that other funding components, particularly their foreign funding costs, have constrained the ability for their mortgage pricing to closely follow the cash rate cycle (Yeates, 2016, 2017). Approximately 35\% of Australian mortgage funding is raised from global financial markets (Ralston \& Davis, 2011; Wilkins, Gardner, \& Chapman, 2016). International borrowing has accounted for around $20 \%$ to $30 \%$ of the total liabilities of Australian banks during the last decade (Turner \& Nugent, 2015). In spite of the importance of this issue, no systematic study has yet empirically investigated the asymmetric relationship in Australia between mortgage rates and the cash rate in the presence of international funding costs. Existing studies on the asymmetric relationship between the cash rate and mortgage rate in Australia (Apergis \& Cooray, 2015; Valadkhani \& Worthington, 2014) do not take into

\footnotetext{
3 Author's calculation from Australian Prudential Regulation Authority [APRA] (2017) and ABS (2017)

“Tables 9-1a and 12", hereafter author's calculation.
} 
account international funding costs. This paper therefore fills this important knowledge gap by investigating the following issues:

1. Does the cash rate still drive the mortgage rate in the presence of the international funding cost?

2. Does the international funding cost significantly affect the mortgage rate?

3. Is there asymmetry in the pass-through of the cash rate and the international funding cost on the mortgage rate?

This study contributes to the literature in two main ways. First, it is the first paper to study the asymmetric relationship between mortgage interest rates and the cash rate in the presence of international funding costs. Although numerous studies, such as those of Apergis and Cooray (2015) and Valadkhani and Worthington (2014), have examined the asymmetric relationship between the cash rate and mortgage rates in Australia, none of these has taken into account international funding costs. Second, this is the first paper to study the asymmetric impact of international funding costs on mortgage rates.

This paper applies two other innovations regarding data and method. Our comprehensive banklevel dataset covers the broadly disaggregated mortgage interest rates of 20 anonymous Australian lenders, which account for approximately $90 \%$ of total outstanding mortgages (author's calculation). This novel dataset enables the exploration of heterogeneous asymmetry. This study is the first empirical analysis of interest rate pass-through (IRPT) to apply the latest asymmetric cointegration single-equation, the NARDL approach of Shin, Yu, and GreenwoodNimmo (2014) in panel form. This Panel NARDL model enables researchers to a) simultaneously examine the asymmetric relationship, both short-run and long-run, and b) capture within group heterogeneity, compared with conventional cointegration techniques.

The remainder of this study proceeds as follows. Section 2 reviews the theoretical framework and relevant studies relating to asymmetric issues in housing credit markets, and then constructs the testable hypotheses. Section 3 describes the data and outlines the methodology. Section 4 presents and discusses the empirical results; Section 5 draws conclusions. 


\section{Literature Review and Hypothesis Development}

\subsection{Theoretical Framework: The Marginal Cost Pricing Model}

Two prominent theoretical frameworks for banks' interest rate setting are the marginal cost pricing model of De Bondt (2005) and Rousseas (1985) and the industrial organization (IO) approach by Freixas and Rochet (2008). The former explores banks' marginal pricing costs, while the latter focuses on key factors such as competitive pricing, market power, monopolistic competition, and bank characteristics. The empirical literature on bank price-setting, such as Gambacorta (2008), commonly employs both approaches to determine retail interest rates in the long term in the following equation.

$Y_{i, t}=\alpha_{i}+\beta^{\prime} X_{i, t}+\varepsilon_{i, t}$

where $Y_{i, t}$ is the retail interest rate; $\alpha_{i}$ and $\varepsilon_{i, t}$ are the constant and error term, respectively; $X_{i, t}$ is a vector of those explanatory variables; and $\beta^{\prime}$ is a vector measuring the effect of each exogenous factor on the retail rate.

This paper, which confines itself to the transmission of banks' marginal pricing costs, is categorized as a part of the IRPT literature or retail interest rate adjustments (e.g., Apergis \& Cooray, 2015; De Bondt, 2005; De Haan \& Sterken, 2011; Fuertes, Heffernan, \& Kalotychou, 2010). Bank interest rates are determined by different factors; however, the most substantial determinant is marginal funding costs because they are market-based sources for retail bank rate pricing. The movements of retail bank rates and funding costs are typically approximated by the money and capital market rates. The marginal cost pricing model of De Bondt (2005) has been widely employed in the IRPT literature to examine the nature of this transmission mechanism. The principle of this model is that depository institutions price their retail interest rates as a profit margin over their variable input costs of funds. This study, following the IRPT literature, focuses on examining the heterogeneous asymmetry at the Australian bank level; therefore, the application of the De Bondt (2005) approach is appropriate. In this context, Eq. (1) has been simplified to examine long-term interest rate pass-through as follows.

$b r_{i, t}=\mu_{i}+\beta m r_{i, t}+\varepsilon_{i, t}$

where $b r_{i, t}$ is the interest rate set by bank $i$ at time $t$ and $m r_{i, t}$ is the marginal cost of funds approximated by a policy rate and/or a money market interest rate. The constant markup, $\mu_{i}$, 
and the long-term pass-through coefficient, $\beta$, reflect the efficiency of this transmission. Variations in retail rates are measured by the variations in the cost-of-funds rates, depending on the size of $\beta$. Correlation analysis or maturity matching of market interest rates is used to select the cost-of-funds rate. The empirical examinations of the interest rate transmission, applying this method, have been classified into the cost-of-funds approach.

Theoretically, in a perfectly competitive market, changes in market rates (funding costs) should be completely and symmetrically transmitted into retail bank interest rates, exhibited by a passthrough parameter $(\beta)$ equal to unity. However, in a real economy, banks operate in an imperfectly competitive market, which induces asymmetric pricing patterns ( $\beta$ is unequal to unity), in two scenarios: positive and negative. When depository institutions respond to movements in funding costs, they slowly lower (raise) their lending rates (deposit rates) downwards (upwards), while scrambling to increase (decrease) lending rates (deposit rates) upwards (downwards), resulting in a positive asymmetry. This positive asymmetry in lending rates enables banks to extract surplus from their borrowers. Conversely, negative asymmetries, which occur when these adjustments on loans (deposits), are more sluggish for upward (downward) changes in funding costs and, vice versa, are not bank preferences because they offer more benefits to customers. Therefore, a funding cost shock in Eq. (2) is split into positive and negative shocks associated with funding cost rises and cuts respectively, and this equation has been converted into

$b r_{i, t}=\mu_{i}+\beta_{i}^{+} m r_{i, t}^{+}+\beta_{i}^{-} m r_{i, t}^{-}+\varepsilon_{i t}$

where $\beta_{i}^{+}$and $\beta_{i}^{-}$are asymmetric long-run parameters; and $m r_{i t}^{+}$and $m r_{i t}^{-}$represent the positive and negative shocks for respectively funding rate rises and cuts.

\subsection{Review of Asymmetric Mortgage IRPT Studies}

Empirical studies of asymmetric interest rates pass-through are extensive in regard to data types, country selections, and various techniques and procedures, while the existing literature on asymmetric adjustments in mortgage interest rates, including this critique, is confined to highly developed markets. Both single-country studies (Fuertes et al., 2010; Valadkhani \& Worthington, 2014) and cross-country analyses (Apergis \& Cooray, 2015; Belke, Beckmann, \& Verheyen, 2013; De Bondt, 2005) have recently focused on asymmetric adjustments in mortgage rates, owing to the increasing importance of mortgage markets since the 2008-09 Global Financial Crisis (GFC). 
We categorize available analyses of empirical results and findings for mortgage borrowers into two groups: favorable and unfavorable. Several studies (De Haan \& Sterken, 2011; Liu et al., 2011; Lowe \& Rohling, 1992) provided downward or negative asymmetry results supporting the customer preference hypothesis of Neumark and Sharpe (1992). Banks in the Dutch, New Zealand, and Australian mortgage markets are quicker to reduce their housing interest rates when responding to downward movements in market rates but are slower to increase these rates when responding to market rate rises. Explanations in the literature for this finding are heterogeneous. Lowe and Rohling (1992) suggested that credit rationing that helped banks mitigate unsecured home loans during the historical record high of housing rates in Australia, from $11 \%$ to $16 \%$ annually during the period 1985:4-1991:4. The findings of Liu et al. (2011) support the adverse customer reactions hypothesis, that New Zealand banks precluded severe losses in housing loans by accepting lower margins. In contrast, the majority of previous studies confirm the collusive pricing agreement hypothesis of Hannan and Berger (1991), with significantly upward asymmetry in the Australian, Canadian, UK, and US mortgage markets (e.g., Allen \& McVanel, 2009; Apergis \& Cooray, 2015; Valadkhani \& Anwar, 2012; Valadkhani \& Worthington, 2014). For instance, the Australian mortgage interest rates are immediately increased $120 \mathrm{bp}$ in response to a unit cash rate hike, but are only reduced around 85 bp corresponding to a unit cash rate cut (Valadkhani \& Anwar, 2012).

We briefly critique several main issues in the literature relating to data, nonlinear techniques, and procedures. Although both time series and panel data features are used, the mainstream literature employs aggregate mortgage rates on a country level (e.g., Liu et al., 2011; Valadkhani \& Anwar, 2012). Using an aggregated measure of averaged mortgage interest rates across depository institutions might create spurious results, due to heterogeneity issues or failure to detect the asymmetry evidence (De Graeve, De Jonghe, \& Vennet, 2007). The use of bank-level data is rare due to its confidential information. A few studies in Australia (Valadkhani \& Worthington, 2014), UK (Fuertes et al., 2010), Canada (Allen \& McVanel, 2009), and Netherlands (De Haan \& Sterken, 2011) employ disaggregated data of transaction housing rates, with a relatively long period, that offer more accurately estimated results. However, these studies are limited by the number of major banks in their samples, except for Fuertes et al. (2010). All prior studies used administrated mortgage rates. To the best of our knowledge, very few existing studies (Allen \& McVanel, 2009; Haan \& Sterken, 2011; Valadkhani \& Anwar, 2012; Valadkhani \& Worthington, 2014) have investigated both shortterm degree and speed of asymmetric adjustments of mortgage rates, while the remaining 
studies examine only the short-term adjustment speed. This arises from a major shortcoming of the two-step approach embracing the Threshold Auto-Regressive (TAR), the Momentum TAR, and the Band TAR models, which are used in these studies. The two-step approach enables researchers to detect the existence of asymmetric cointegration among interest rates. However, it allows only the detection of short-term asymmetry and/or sign asymmetry in the error-correction term. The latest single-equation cointegrating technique, the NARDL model introduced by Shin et al. (2014), contributes to the literature by investigating simultaneously both short-term and long-term asymmetry in the IRPT within a single equation. Numerous researchers, such as Atil, Lahiani, and Nguyen (2014), have subsequently employed this method to examine asymmetry in commodity prices. Apergis and Cooray (2015) are the first to employ this model in their cross-country examination of asymmetry in the IRPT based on the quarterly time-series data of the selected largest banks in the US, UK, and Australia. However, these researchers construct the lending rate variable from interest rates on the consumption, housing, and corporate loans of the largest national banks. None apply this technique in panel form.

Overall, the novelty of our study is threefold. We employ the novel bank-level data of the weekly variable interest rates on owner-occupied mortgages. This is the first Panel NARDL analysis to draw a comprehensive picture of heterogeneous asymmetry in mortgage rate transmission. We also shed light on the asymmetric response of owner-occupied housing rates to international funding costs.

\subsection{Hypothesis Development}

\section{The effect of the foreign funds rate and cash rate on bank mortgage rates}

We hypothesize that both the cash rate and the foreign-funds rate significantly affect the bank mortgage rate setting in Australia. This testable hypothesis is formed from the marginal cost pricing model of De Bondt (2005) in Eq. (2), which assumes retail bank interest rates are set as a profit margin (markup) over the marginal cost of funds. Banks raise funds for mortgage financing from different sources, so their marginal cost-of-funds rate is mainly determined from variations in the funding costs. This marginal funding rate for Australian banks should be measured by both domestic and foreign funds rates. The cash rate is still a key indicator of domestic deposits (Wilkins et al., 2016) and has commonly been the proxy for money market rates in the IRPT studies (Apergis \& Cooray, 2015; Valadkhani \& Worthington, 2014). At an 
individual level, banks' significant exposure to international funding sources is anticipated to affect their mortgage price-setting. The first hypothesis is constructed as:

Hypothesis 1: The cost of foreign funds is expected to affect bank mortgage rates, in addition to the cash rate.

\section{Asymmetric movements of the funds rates and mortgage interest rates}

As approximated in Eq. (2), a mortgage rate is set as a constant markup over the overall funding cost. Primary factors affecting this markup at the individual bank level are credit risks, administration costs, and monopolistic competition associated with market power (Freixas \& Rochet, 2008). We start with the credit rationing hypothesis and adverse customer reactions articulating with the adverse selection and moral hazard arising from the information asymmetry theory of Stiglitz and Weiss (1981). When mortgage interest rates decrease, the mortgage supply will typically increase. The increases in lending stock with rate cuts tend to attract new, riskier borrowers, resulting in a greater increase in mortgage rates to compensate banks for higher expected defaults. Hence, a cut in the policy rate and/or market rates may cause the markup to rise, or vice versa, and may contribute to upward asymmetry in bank pricesetting. Conversely, when mortgage rates increase, banks tend to replace their significant increases in lending rates with credit rationing to preclude them from attracting less creditworthy mortgagors, resulting in an upward rigidity or downward asymmetry. They can offer their clients interest rate options for a certain time span. This practice can trigger positive asymmetry and a greater markup because banks recoup these alternative costs instead. Nonetheless, if banks increase the stock of mortgages in response to policy rate cuts, they may use foreign funds more frequently than previously, so the marginal cost of borrowing may escalate. The observed asymmetries may be attributable to the escalating cost of funds, and may possibly be a short-run phenomenon.

Competition is the prominent theory in explaining the IRPT asymmetry, both negative and positive. Banks operating in a highly competitive market adjust their retail rates quickly and completely to policy and/or market rate changes and have smaller long-term markups than in a weak, contestable market. Intense competition induces banks to be not only quicker to reduce their lending rates in response to market rate cuts, but also slower to increase their rates when responding to market rate rises (De Bondt, 2005; De Haan \& Sterken, 2011; Liu et al., 2011). Hence, this results in negative asymmetry favoring mortgage borrowers. The key explanation 
for this pricing conduct is that banks are becoming more constrained by the risk of losing customers, so they will reluctantly increase lending rates upwards (Neumark \& Sharpe, 1992). This theory has been validated in advanced mortgage markets, such as the Dutch, New Zealand, and Australian (see De Haan \& Sterken, 2011; Liu et al., 2011; Lowe \& Rohling, 1992).

Conversely, the key premise and the empirical evidence for the common occurrence of positive asymmetry are monopolistic competition associated with market concentration (e.g., Apergis \& Cooray, 2015; De Bondt, 2005; Van Leuvensteijn et al., 2013). In a highly concentrated or oligopolistic market, banks that wield market pricing power can exert asymmetry in setting their mortgage rates (Corvoisier \& Gropp, 2002; De Graeve et al., 2007). When market competition is weak, banks are sluggish to reduce their lending rates when money market rates are decreasing, but faster to increase their rates in response to market rate rises, resulting in upward asymmetry or a positive expected profit. Overall, a lower (greater) markup of bank mortgage price-setting in the long term can be attributable to intense (weak) market competition. Positive asymmetry also arises from market power which enables collusive pricing behavior. The more concentrated the market, the more likely lenders are tacitly collusive. If the assumption of bank collusion exists, banks adjust their lending interest rate upwards faster than downwards as a consequence, while deposit rates exhibit the opposite pattern (Hannan \& Berger, 1991).

The Australian banking and mortgage financing systems are highly oligopolistic. Four major Australian-owned banks (ANZ, NAB, CBA and WBC, hereafter the Big-4) possess around $75 \%$ of the total sector assets and have issued $80-85 \%$ of total outstanding bank mortgages since the GFC (author's calculation). Consequently, they dominate both banking and mortgage markets. The level of bank concentration is relatively high, globally (International Monetary Fund [IMF], 2012) so that banks to some extent can exercise market power in conducting a less contestable mortgage pricing policy. Hence, we have developed the following hypothesis on Australian banks' asymmetric mortgage pricing conduct:

Hypothesis 2: Australian banks reduce their mortgage rates more sluggishly in response to cash rate and foreign funds rate reductions, while increasing their rates more speedily to these funds rates increases. 


\section{The GFC impact on the IRPT}

In banking markets, concentration is negatively associated with competition (Corvoisier \& Gropp, 2002; Khan, Kutan, Ahmad, \& Gee, 2017). The increasing concentration of the Australian mortgage market is attributable to the withdrawal of the wholesale lenders in 2007 and banks' acquisitions in 2008. The combined market share of the Big-4 banks increased significantly from 64\% in December 2007 to 85\% by December 2016 (author's calculation). Subsequently, market contestability has significantly declined, reflected in a surge in the Boone indicator as shown in Figure 2.

\section{[Insert Figure 2 here]}

As seen in Figure 2, until 2007 the Australian market was the most contestable for mortgages. In line with Canada's, it was much more competitive than the Dutch and New Zealand markets, which are oligopolistic, ${ }^{4}$ or Norway's and the world advanced market average. However, since the GFC related consolidation in 2008, Australia has dislodged itself to become the most fiercely contested market for small banks, with a surge in its Boone indicator to the highest level. Canada's competition has remained stable at the pre-crisis level, and New Zealand's has turned into the most competitive market, reflected in a dramatic plunge in its Boone index. This significant reduction in competitive pressure associated with the highly concentrated market can induce asymmetry and a greater long-run markup because of increases in dominant banks' market pricing power. Asymmetry also can occur in the post-crisis period because of increases in bank funding costs (Cifarelli \& Paladino, 2016; ECB, 2013). Australian mortgage lenders have shifted their short-term into long-term wholesale borrowing since the GFC (Deans \& Stewart, 2012), so they are unlikely to finance mortgages with foreign funds cheaper than prior to the crisis.

Post-GFC onwards, the widening spread of retail bank interest rate over policy and/or money market rates has dramatically increased, remaining at a high level. This phenomenon occurred not only in Australia but also in the Euro area. Recent studies (Aristei \& Gallo, 2014; Hristov et al., 2014) have examined the GFC impact on the pass-through mechanism in the Euro markets and have found a declining pass-through of policy rates on the lending interest rate. In

\footnotetext{
4 The Big-6 commercial banks accounted for $65 \%$ of Canada's market share during the 2000s (Allen \& McVanel, 2009). The Big-4 Dutch Banks supply approximately $83 \%$ of the total mortgage market share (De Haan \& Sterken, 2011). The Big-4 Australian bank subsidiaries dominate the New Zealand banking industry, with $90 \%$ of the total industry assets (Liu et al., 2011).
} 
Australia, Lim et al. (2013) have documented a continuing decline since the end of 2009, and has attributed this impairment to the funding cost increases since the GFC. Notably, Apergis and Cooray (2015) found significant evidence of asymmetry in Australian Big-4 banks during the post-crisis period, but insignificant asymmetric results for the US and UK samples. Therefore, the third hypothesis is established:

Hypothesis 3: Pass-through speed and degrees after the GFC from foreign funds rate to mortgage rates are expected to be greater than those before and during the GFC.

\section{Methodology}

\subsection{Data and Variable Measures}

The dataset, which spans a 13-year period 2002:7-2015:12, includes 14,120 weekly mortgage rate observations obtained from official sources. Our data have covered the mortgage boom period since 2000, with a surge in mortgage debt outstanding as a percentage of GDP from $40 \%$ to just over $100 \%$ (author's calculation). Also, this dataset allows researchers to capture any potential structural changes due to the GFC.

We employed a novel weekly dataset for 20 out of 37 anonymous sampling banks, splitting them into three groups: four major banks, three foreign subsidiaries, and 13 regional banks. Currently, 152 authorised deposit-taking institutions (ADIs) operate in the Australian mortgage market, comprising 4 major and 26 small Australian-owned banks, seven foreign subsidiary and 45 foreign-owned bank branches, four building societies and 58 credit unions (APRA, 2017). Most ADIs provide home loans. However, these building societies and credit unions were eliminated from our sample because their combined share, equivalent to the securitisation share, is negligible at less than 5\%, while 82 banks dominate the market at $90 \%$ of the total (APRA, 2017; ABS, 2017 “Table 12”). We also excluded all 45 foreign branches, since they do not locally hold capital and are mainly supervised by their home prudential regulations. Macquarie and ING Bank have currently granted a significant number of home loans, but they are not included in the sample due to data unavailability spanning the whole sampled period. Other banks do not allow for assembling consistent data over the study period. Our 20 banks, after sampling, account for approximately $90 \%$ of total outstanding mortgage loans (author's calculation). The representativeness of the sampled banks is well exemplified, based on their mortgage credits. 
Prior research in Australia mainly assesses the asymmetric mortgage pricing practices of the four largest lenders (Apergis \& Cooray, 2015; Valadkhani \& Worthington, 2014). Other researchers focus on the whole banking sector (Valadkhani \& Anwar, 2012). This paper differs from previous studies in that our four subsamples - sector, foreign subsidiary, major bank, and regional groups - are constructed from 20 sampling banks to examine the mortgage rate responses to changes in both cash rate and foreign-funds rate, for each group. We classify the sample based on the oligopoly of the Australian banking system. Major banks which are more well-capitalized play important roles in the transmission in either monopolistic or oligopolistic markets (Baglioni, 2007). Although Australian banks' growth rate of foreign borrowing has been decreasing since the GFC, the volume remains high, equivalent to $35 \%$ of the mortgage funding (Ralston \& Davis, 2011; Turner \& Nugent, 2015). Most of this debt is held by the Big4, whereas the regional banks hold a negligible amount. Hence, we expect that the Big-4 are likely to respond more strongly to changes in foreign funding costs than the regional group will. Moreover, foreign banks in Australia source over 25\% of their funding from overseas deposits through their parent banks and offshore intra-groups, while Australian owners have only about $6 \%$ of offshore deposits (Bailey, Uffelen, \& Wood, 2012). The foreign group has also shifted their funding from short-term wholesale debt to long-term sources. This group, therefore, is anticipated to strongly respond to foreign funding costs in both the short and the long term.

We employed the weekly mortgage rate variable, ER, from the annual adjustable percentage rate of mortgages, the so-called effective mortgage rate that covers all types of fees. Only standard adjusted rate mortgages (ARMs) with 25 to 30 years' maturity and the loan amount of A $\$ 250,000$ for owner occupiers ${ }^{5}$ are selected to make a compatible dataset. The $\mathrm{ER}_{\mathrm{t}}$ data were gathered by various methods because their sources are unavailable in datasets. For the period 2002:7-2012:8, these rates were taken from Cannex's survey of Australian lenders, which was purchased by Griffith University. For the period 2012:9-2015:12, the rates at monthly frequency were manually collected from Info Choice Pty Ltd, and converted into weekly intervals, based on bank announcements of mortgage rate changes. This makes the full

\footnotetext{
${ }^{5}$ Loans to households: Housing: Owner-occupied is the value of housing loans to Australian households for the construction or purchase of dwellings for owner occupation, and revolving credit or redraw facilities originally approved for the purpose of predominantly owner-occupied housing (APRA, 2017).
} 
sample well matched. We created the mortgage rate variables for Sector, Foreign, Major, and Region panels for respective use in our estimations.

In Australia, CR, the official cash rate (the interest rate paid on overnight funds), ${ }^{6}$ is the exogenous policy rate in the IRPT studies. Existing empirical studies (Apergis \& Cooray, 2015; Valadkhani \& Anwar, 2012) of monetary policy transmission mechanism employ policy rates as the exogenous interest rates, as they are direct measures of monetary policy stances. The cash rate is still a key mainstream funding indicator of domestic funds sources (Wilkins et al., 2016). The weekly cash rate is an appropriate proxy for the domestic funds rate of mortgages, owing to its strong influence on bank national funding sources. The cash rate data was publicly retrieved from the RBA website.

We represented the international funding cost variable, BB, by the 3-month $\mathrm{A} \$$ bank bill swap rate (BBSW). ${ }^{7}$ This rate was commercially obtained from the Bloomberg database. Using the BBSW to proxy for the foreign-funds rate is better than using the US\$ LIBOR. Australian banks typically reference the former when sourcing their international funding in both onshore and offshore financial markets, while the latter is a benchmark rate for offshore issues only (Guttmann \& Rodgers, 2015; RBA, 2006). Technically, currency converting errors are eliminated when using the BBSW instead of the LIBOR. However, banks borrow half overseas liabilities in US dollars, and they swap the debt into fixed or floating home currency contracts through foreign exchange swaps and/or currency swaps to hedge against the currency risk (Turner \& Nugent, 2015). Overseas and domestic funding issues with the same maturity thus have comparable effective costs.

\subsection{Empirical Estimation: The Panel NARDL Model}

The NARDL approach of Shin et al. (2014) using panel data is the framework for researchers to capture heterogeneous asymmetry in mortgage rate pass-through in this analysis. This is a dynamic heterogeneous panel (Panel ARDL) representation of the NARDL prism, hereafter the Panel NARDL. The mean group estimator (MGE) (Pesaran \& Smith 1995) and the pool

\footnotetext{
${ }^{6}$ Table F01, RBA database, http://www.rba.gov.au/statistics/tables/index.html\#interest-rates

7 The 3-month BBSW represents the midpoint of the nationally observed best bid and best offer for AFMA Prime Bank Eligible Securities, including bank accepted bills and negotiable certificates of deposit; it is used to provide reference interest rates for the pricing and revaluation of Australian dollar derivatives and debt securities such as floating rate bonds.
} 
mean group estimator (PMGE) (Pesaran et al. 1999) are two well-known techniques employed in the estimations of the Panel ARDL model. They both enable estimates of nonstationary heterogeneous panels for a large sample. The MGE allows all parameters-short- and longterm dynamics, error correction terms, and intercepts - to be heterogeneous across banks, while the long-term coefficients of the PMGE are constrained to be homogeneous across individual banks $i=1,2, \ldots, N$, and the remainder freely differ. The latter is our main focus because long-term homogeneity is well corroborated in the IRPT literature.

The Panel NARDL method is distinct from the prevailing asymmetric cointegrating techniques, such as the ECM, the TAR, and the Smooth Transition ECM, because it jointly models cointegration and asymmetry dynamics in a single equation and releases the nonstationary assumption. The Panel NARDL model is ideal for heterogeneous asymmetric pass-through studies. First, this approach simultaneously captures both short-term and long-term asymmetries, while the conventional techniques address asymmetry in the speed of the disequilibrium and/or in the short term only. Moreover, sign asymmetry and/or duration of disequilibrium can be observed in a graphical presentation of cumulative dynamic multiplier effects produced in the NARDL without modelling the asymmetric error correction parameter. Second, hidden cointegration can be also omitted when using linear models. ${ }^{8}$ The innovation of the NARDL framework is in decomposing the exogenous variables into positive and negative partial sums, which enables the detection of hidden cointegrating relations between variables and avoids omitting this link in the estimation procedure. This method is able to differentiate between nonlinear cointegration, linear cointegration, and the absence of cointegration. With this detection ability, the NARDL approach is more accurate and more efficient in examining the asymmetric relationship among economic variables. Third, the Panel NARDL model by design enables researchers to achieve sharper estimates and stronger inference by exploring both the time- and cross-section variation in panel datasets rather than using time-series techniques.

In this study, we embed the NARDL prism of Shin et al. (2014) in a panel ARDL to yield the Panel NARDL $(p, q)$, or a nonlinear Panel ARDL model for the disaggregated mortgage rate adjustment by bank $i$ at time $t$. To preserve space, we reproduce only the asymmetric Panel NARDL model. In this model, the cost-of-funds rate, $m r_{i t}$, is decomposed into positive and

\footnotetext{
${ }^{8}$ Hidden cointegration exists if two time series are not cointegrated in the conventional sense, but their positive and negative components are cointegrated (Granger \& Yoon, 2002)
} 
negative partial sums, $m r_{i t}^{+}$and $m r_{i t}^{-}$, respectively responding to funding cost increases and decreases:

$$
m r_{i t}^{+}=\sum_{j=1}^{t} \Delta m r_{i j}^{+}=\sum_{j=1}^{t} \max \left(\Delta m r_{i j}, 0\right) ; m r_{i t}^{-}=\sum_{j=1}^{t} \Delta m r_{i j}^{-}=\sum_{j=1}^{t} \min \left(\Delta m r_{i j}, 0\right)
$$

where $m r_{i t}=m r_{i 0}+m r_{i t}^{+}+m r_{i t}^{-}$. The initial value, $m r_{i 0}$, can be set to zero. In this analysis $m r_{i t}$ is either $B B_{i t}$ or $C R_{i t}$.

We formulate the Panel NARDL $(p, q)$ model for the transaction mortgage interest rate, $E R_{i t}$, set by bank $i$ at time $t$ by embedding Eqs. (3) and (4) within a Panel ARDL (p,q) as follows:

$$
\begin{aligned}
\Delta E R_{i t}=\mu_{i}+ & \rho_{i} E R_{i, t-1}+\delta_{i}^{+} m r_{i, t-1}^{+}+\delta_{i}^{-} m r_{i, t-1}^{-}+\sum_{j=1}^{p-1} \lambda_{i j} \Delta E R_{i, t-j}+\sum_{j=0}^{q-1}\left(\pi_{i j}^{+} \Delta m r_{i, t-j}^{+}\right. \\
& \left.+\pi_{i j}^{-} \Delta m r_{i, t-j}^{-}\right)+\varepsilon_{i t}
\end{aligned}
$$

where the long-run parameters of interest are the IRPT asymmetries given by $\beta_{i}^{+}=-\delta_{i}^{+} / \rho_{i}$ and $\beta_{i}^{-}=-\delta_{i}^{-} / \rho_{i}$. The superscripts (+) and (-) in Eq. (5) denote the positive and negative partial sums defined in Eq. (4). The symbols $p$ and $q$ refer to the optimal lag orders of the variables in the distributed lag part, while the constant markup and error terms are $\mu_{i}$ and $\varepsilon_{\text {it. }}$ The first different operator and error correction term are denoted by $\Delta$ and $\rho_{i}$. The short-run impacts of funds rate rises and cuts on $E R_{i t}$ are the significant coefficients collected in the vector $\left(\pi_{i, 0}^{+}, \ldots, \pi_{i, q-1}^{+}, \pi_{i, 0}^{-}, \ldots, \pi_{i, q-1}^{-}\right)^{\prime}$. The NARDL prism enables estimating unbiased longterm coefficients and obtaining the better inferences, even in the presence of weakly endogenous nonstationary explanatory variables and without any assumption imposed (Shin et al., 2014). These coefficients are theoretically positive, while short-term parameters can be either positive or negative because many factors can simultaneously affect the transmission at the funding cost shocks.

The Shin et al. (2014) bootstrap testing is implemented to plot the cumulative dynamic multiplier effect of a unit change in $m r_{i t}^{+}$and $m r_{i t}^{-}$on $E R_{i t}$. These cumulative dynamic multipliers ascertain the evolution of the effective mortgage rates over the horizons $h=0,1$, $\ldots, H$ in response to a unit increase and decrease, respectively, of the funds rates in period $h=0$. The combination of these positive and negative cumulative dynamic multipliers therefore measures the IRPT asymmetry at horizon $h$ and can be recursively obtained: 


$$
m_{i h}^{+}=\sum_{j=0}^{h} \frac{\partial b r_{i, t+j}}{\partial m r_{i, t}^{+}} ; \quad m_{i h}^{-}=\sum_{j=0}^{h} \frac{\partial b r_{i, t+j}}{\partial m r_{i, t}^{-}} \text {with } h=0,1,2, \ldots
$$

Note that as $h \rightarrow \infty$, then $m_{i h}^{+} \rightarrow \beta_{i}^{+}$, and $m_{i h}^{-} \rightarrow \beta_{i}^{-}$hence, the dynamic multipliers represent the traverse from the short run to the long run. Bootstrap confidence bands around $m r_{i t}^{+}-m r_{i t}^{-}$ can be utilized to test whether the asymmetry at horizon $h$ is statistically significant. The NARDL does not model asymmetry in the speed of adjustments on $\rho_{i}$, but this approach still enables exploration and testing for sign asymmetry at any desired horizon.

Three established hypotheses can be reiterated based on the estimated equations as follows:

Hyp. 1a (Zero impact IRPT) $H_{0}^{1 a}: \pi_{i, 0}=0$ vs $H_{A}^{1 a}: \pi_{i, 0} \neq 0$.

Hyp. 1b (Complete long-run IRPT) $H_{0}^{1 b}: \beta_{i} \geq 1$ vs $H_{A}^{1 b}: \beta_{i}<1$.

Hyp. 1c (Negative speed of adjustments) $H_{0}^{1 c}: \rho<0$ vs $H_{A}^{1 c} \rho>0$.

Hyp. 2a (Zero asymmetric impact IRPT) $H_{0}^{2 a+}: \pi_{i 0}^{+}=0$ vs $H_{A}^{2 a+}: \pi_{i 0}^{+} \neq 0$ for funds rate rises; likewise, $H_{0}^{2 a-}: \pi_{i 0}^{-}=0$ vs $H_{A}^{2 a-}: \pi_{i 0}^{-} \neq 0$ for funds rate cuts.

Hyp. 2b (Complete asymmetric long-run IRPT) $H_{0}^{2 b+}: \beta_{i}^{+}=-\delta_{i}^{+} / \rho_{i} \geq 1$ vs $H_{A}^{2 b+}: \beta_{i}^{+}<1$ for funds rate rises; likewise, $H_{0}^{2 b-}: \beta_{i}^{-}=-\delta_{i}^{-} / \rho_{i} \geq 1$ vs $H_{A}^{2 b-}: \beta_{i}^{-}<1$ for funds rate cuts.

Hyp. 2c (Negative speed of adjustments) $H_{0}^{2 c}: \rho_{i}<0$ vs $H_{A}^{2 c} \rho_{i}>0$.

Hyp. 3a: (Asymmetric impact IRPT) $H_{0}^{3 a}: \pi_{i t P o s t_{G F C}}^{\mp}>\pi_{\text {itPre \& during }}^{\mp}$ for foreign fund rate changes; likewise, $\pi_{i t P o s t}^{\mp} t_{G F}<\pi_{i t P r e ~ \& \text { during }_{G F C}}^{\mp}$ for cash rate changes.

Hyp. 3b: (Asymmetric long-run IRPT) $H_{0}^{3 b}: \beta_{\text {iPost }_{G F C}}^{\mp}>\beta_{\text {iPre \& } \text { during }_{G F C}}^{\mp}$ for foreign fund rate changes; likewise, $\beta_{i P o s t_{G F C}}^{\mp}<\beta_{i P r e ~ \& \text { during }_{G F C}}^{\mp}$ for cash rate changes.

Hyp. 3c: (Comparing speed of adjustments) $H_{0}^{3 c}: \rho_{i P o s t_{G F C}}>\rho_{\text {iPre and during }}$ for the

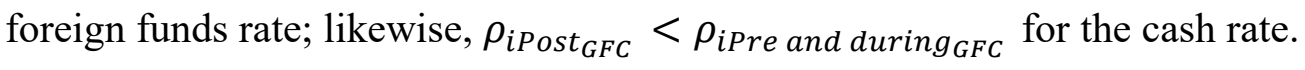

Symmetric (linear) Panel ARDL and asymmetric (nonlinear) Panel NARDL estimates in this analysis are performed with both the MGE and PMGE. These estimated results are subjected 
to the Hausman test to select the more efficient method. The Hausman test results reported in Tables 3 to 6 in the following section significantly favor the PMGE with the non-rejection of the null hypothesis for virtually all linear and for all nonlinear estimates. The PMGE is a more appropriate technique for estimating the nexus of mortgage rates and funds rates in either symmetry or asymmetry specifications. Our Hausman test results are consistent with the compromise of homogeneous long-term pass-through in the literature. Hereafter, we reveal and discuss the PMGE results only.

\section{Empirical Analysis}

\subsection{Preliminary Analysis}

We first visualize the possible alignment between the effective mortgage rate, ER $\mathrm{R}_{\mathrm{it}}$, and the funds rates, $\mathrm{BB}_{\text {it }}$ and $\mathrm{CR}_{\mathrm{it}}$, over the sample period 2002:7-2015:12 (see Figure A.1, Appendix A). This potential interaction appears clearly perceptible for both cash rate and foreign funds rate, given the slump of the 2008-09 GFC. A strongly positive cointegration between mortgage rates and the cost-of-funds rates prevails among sampled banks. The well-cointegrated relationships between (1) $\mathrm{ER}_{\mathrm{it}}-\mathrm{BB}_{\mathrm{it}}$ and (2) $\mathrm{ER}_{\mathrm{it}}-\mathrm{CR}_{\mathrm{it}}$ are substantiated by a Pairwise cointegration test at 0.853 and 0.849 , respectively. However, two exogenous funding cost variables, $\mathrm{BB}_{\mathrm{t}}$ and $\mathrm{CR}_{\mathrm{t}}$, are highly linearly related at 0.989 , which is likely to be perfect multicollinearity. Interest rate series are dominated by smooth, long-term trends, so that these variables can behave individually as nonstationary random walks. All econometrics procedures hereafter are performed separately as (1) $\mathrm{ER}_{\mathrm{it}}-\mathrm{BB}_{\mathrm{it}}$ and (2) ERit-CRit to avoid spurious estimated results.

Deeper consideration shows that these data series experienced an extreme downward period, 2008-2009, as the repercussion of the GFC. The recession created the market restructuring and tightening credit conditions, resulting in the downward trend of the funding costs and mortgage rates. The declining magnitudes of mortgage rates and funding costs have been much wider since 2008. Time breaks can occur in the series due to the extreme shocks, and these variables possibly incorporate the nonlinear properties (Kwapil \& Scharler, 2013), so examining the effect of the GFC on the pass-through is necessary. A sub-sample analysis is obtained by splitting the initial sample into pre-GFC, GFC, and post-GFC spans. We selected the breakpoint July 1, 2007 for the pre-GFC subsample 1997:1-2007:6 because of the September downfall of Northern Rock, one of the five largest British mortgage lenders. This collapse 
triggered the 2007 UK credit crisis and significantly affected Australian banking and mortgage markets. Funding costs have significantly increased since the ensuing global banking crisis of 2008-2009, locally and internationally. Assessing bank pricing behaviour during the GFC 2007:7-2009:12 and in the post-crisis period 2010:1-2015:12 is essential because of its abnormality. We also exclude a regional bank coded by $\mathrm{ID}_{15}$ from the post-crisis sub-sample because of its merger in 2010 .

Bartlett's mean equality test and the Panel Analysis of Covariance (PANCOVA) are employed to justify the sub-samples into pre-GFC, GFC, and post-GFC. We compare the mean differences for the three sub-spans because extreme economic shocks, such as the GFC, induce dramatic structural changes, both instantaneous and gradual, in the means of variables. Structural breaks imply a multiple regression relationship between dependent and independent variables with different intercepts and/or slopes, resulting in spurious estimated regression results. The Bartlett test (see Table A.1) tests for possible shifts in the means of the driven variable, ER, across the GFC sub-samples, but says nothing about the response of the regressors, $\mathrm{CR}$ and $\mathrm{BB}$, in relation to such shifts. As a complementary analysis, we further test whether there are statistically significant differences, regarding the impact of $\mathrm{CR}, \mathrm{BB}$, or both on ER, across the sub-samples and whether such partitioning is necessary. If the regressors are immune to such shifts, the separate regressions for the GFC sub-samples are not expected to yield statistically different results. Therefore the full sample analysis will suffice. The underlying Panel ARDL form of Eq. (2) for this analysis including relevant terms is specified below:

$$
\begin{gathered}
\Delta E R_{i t}=\mu_{i}+\rho_{i} E R_{i, t-1}+\delta_{i} m r_{i, t-1}+\gamma_{1 i} D C^{*} m r_{i, t-1}+\gamma_{2 i} D A^{*} m r_{i, t-1} \\
\sum_{j=1}^{p-1} \lambda_{i j} \Delta E R_{i, t-j}+\sum_{j=0}^{q-1} \phi_{i j} \Delta m r_{i, t-j}+\varepsilon_{i t}
\end{gathered}
$$

where DC takes the value of zero and then one for the crisis and the aftermath, while DA is zero and then one after the crisis. The Wald test is then used to test whether the coefficients on the relevant interaction terms are statistically different from zero, whether individually or jointly. Thus, there are three testable research hypotheses: $H_{0}: \gamma_{1 i}=0 ; H_{0}: \gamma_{2 i}=0$ and $H_{0}: \gamma_{1 i}=\gamma_{2 i}=0$. A rejection of the null hypothesis, such as $H_{0}: \gamma_{1 i}=0$, implies that there is a statistically significant difference in the impact of the driving variables, either $\mathrm{BB}$ or $\mathrm{CR}$, on ER between pre-GFC and the other two periods (GFC and post-GFC), while a non-rejection 
implies otherwise. For a rejection of $H_{0}: \gamma_{1 i}=0$, the difference in the slope coefficients between the pre-GFC and the period after is given as $\gamma_{1 i}$ while for a non-rejection the slope coefficients are not statistically different, since $\gamma_{1 \mathrm{i}}=0$ technically, and are therefore given as $\delta_{\mathrm{i}}$ in the long run. Other hypotheses follow the same intuition.

As presented in Table A.2, two interesting findings can be discerned. First, the interaction terms are statistically significant for all the groups considered (Sector, Foreign, Major, and Region), implying that such differential effects exist. Therefore, partitioning the data into relevant subsamples is justified. Second, as a form of validation, the results of the Wald test further confirm that the coefficients on the interaction terms are statistically different from zero and are therefore not redundant in the test equation. The overall implication is that the GFC caused a shift in the interest-rate pass-through at the Australian bank level over the period under consideration. In the main analyses we offer distinct results explaining the dynamics in the pass-through for the pre-GFC, crisis, and post-GFC periods.

Understanding the distributional properties of panels with large $T$ before employing the econometrics models is essential because the panel-ARDL approaches are invalid in the presence of $I(2)$ variables. Four disparate groups of panel unit root tests are performed; their results are shown in Table A.3, Appendix A. The results of the Hadri (2000) stationary test in Panel $\mathrm{C}$ confirm that all the variables of each panel are integrated in order one $I(1)$. The nonstationary tests in Panels A and B provide mixed results, but none of the variables is found to be $I(2)$, given the potential of structural breaks in series. The Pesaran (2007) test results validate that the mortgage rates and funds rates are heterogeneous stationary of order $I(1)$. This finding reaffirms our selection of the Panel-ARDL to construct the superior Panel-NARDL framework in this context. Therefore, the Panel NARDL model is ideal for this analysis as it provides a properly accurate measure for inherent heterogeneity, non-stationarity, and nonlinearity in our panel dataset. Our estimated results are threefold. First, the interaction of mortgage rates and funds rates is examined over the full-sample period for both symmetry (Panel-ARDL) and asymmetry (Panel-NARDL). Second, in the sub-sample analysis, we focus on the occurrence of asymmetry before, during, and after the crisis. Third, we consider the pricing behaviour of the Big-4 by performing the NARDL for each bank and plotting multiplier effects for the robustness size asymmetries and the speed of adjustments. 


\subsection{Mortgage Rate Pass-Through: Baseline Results}

This section scrutinizes both the symmetric and asymmetric transmission of bank funding costs to the effective mortgage rates over the full sample period 2002:7-2015:12. Table 1 reports the foreign-funds rate transmission to mortgage rates, while Table 2 presents the cash rate estimated results. In each table, Panels A and B show the linear and nonlinear estimated results, while diagnostics are reported in Panel C.

\section{[Insert Table 1 here]}

We confer the testable results of the foreign-funds rate equations. The adjustment speeds are all significant and negative, validating the long-run association of the $\mathrm{ER}_{t}-\mathrm{BB}_{\mathrm{t}}$ nexus (Null Hyp. 1c). The effect of the foreign funds rate on bank mortgage re-pricing is strongly confirmed in both the short and long term at $1 \%$ level of significance. All groups immediately respond to changes in the foreign-funds rate $(19.7-23.4 \mathrm{bp})$. The Big-4 is the most responsive at $23.4 \mathrm{bp}$, while the region is the most sluggish at $19.7 \mathrm{bp}$. The short-term rigidity findings validate our Hyp. 1a: that is, instantaneous impacts are greater than zero, and also affirm the anticipation of the Big-4's largest foreign fund component. The long-term coefficients are all significant and close to unity (68.4-72.1bp), confirming the incomplete pass-through (Hyp. 1b). These coefficients specify that a $100 \mathrm{bp}$ change in the foreign-funds rate would be transmitted to the mortgage rates from 68.4 to $72.1 \mathrm{bp}$. The region group is the most competitive lender, with the highest size (72.1bp) and speed (4.8\%). Foreign and major lenders are the least contestable at around $68.5 \mathrm{bp}$, lower than the sector average of $70.8 \mathrm{bp}$. The largest long-term markup (16.4bp), found in the region estimation, reflects their highest volatility in the market (discussed in Session 3.1); the two bigger lending groups are relatively stable at just over 10bp markups, owing to their larger economic scale.

The asymmetric results in Panels B and C reaffirm the foreign-funds effect and confirm significant heterogeneous asymmetry in mortgage rate adjustments. The speed coefficients of the mortgage rates to the long-run equilibrium, $\rho_{\mathrm{i}}$, are all significant and negative, confirming the long-run cointegration between mortgage rates and foreign funding costs (Null Hyp. 2c). These parameters significantly improve for all estimations at around 13.3-15bp, compared with the symmetry results at less than $5 \mathrm{bp}$, reflecting the model fit. The impact dynamics reaffirm our anticipated hypothesis that the major bank mortgage rate has been the most responsive to the foreign funds rate because they use the largest component, as discussed in Section 3.1. The 
foreign banks reveal their market pricing power with an upward impact of 8.6bp. Interestingly, the major group greatly reduce their mortgage rate by $20.4 \mathrm{bp}$ in response to a unit rate cut, but increase it by only $2.7 \mathrm{bp}$ to a unit rate rise. The region is the price follower, with insignificant impacts.

In the long term, both increases and decreases in the foreign funds rate exercise significant and considerable impact on mortgage rates in all sampled groups. The magnitude is much greater for positive than for negative, resulting in positive asymmetry or upward asymmetry, which is verified by significant Wald $F$-statistics at $1 \%$ level. The asymmetric magnitudes are closer to unity and are also much greater than the symmetry coefficients. This finding confirms the strong effect of the oligopolistic mortgage market that allows banks to exert market pricing power over their mortgage borrowers in the short and long term, signifying important policy implications regarding competition maintenance and customer protection. Our findings completely validate the long-term asymmetry upwards (Hyp. 2b) in the foreign fundsmortgage rate nexus for all groups; while partially confirming the short-term asymmetry downwards (Hyp. 2a) for the major banks.

\section{[Insert Table 2 here]}

The results of the cash rate-mortgage rate estimations in Table 2 substantiate the cash rate effect, both symmetric and asymmetric, on mortgage rates. The immediate symmetry results (Panel A) reveal that the sampled banks are mostly quiet in response to cash rate changes at low levels to less than $5 \mathrm{bp}$, except the major group at $18.5 \mathrm{bp}$, but only the foreign coefficient is significant. Noticeably, the foreign-funds rate estimations disclose the stronger significance of the $1 \%$ level and the much greater immediate impacts $(19.7-23.4 \mathrm{bp})$ than the cash-rate estimates. This finding signifies that Australian banks are more responsive to instant shocks in foreign funding costs than to cash rate changes. Our finding is consistent with Lim, Tsiaplias, and Chua's (2013) finding, indicating that the cash rate is closely set for macroeconomic purposes. The long-term results are comparatively analogous to the foreign-funds rate estimates, in which the region is the most competitive, while the foreign is the least. These findings partially validate the short-term rigidity and cash rate effect on bank mortgage pricing (Hyp. 1a), but fully affirm the long-term incompleteness (Hyp. 1b). Our findings also indicate the market power of the major banks, resulting from the oligopoly of the banking sector, signifying asymmetry in mortgage price-setting. 
The asymmetric results of the cash rate transmission are reported in Panels $2 \mathrm{~B}$ and C. The Big4 certainly exerts their market power, with the smallest and insignificant impacts both positive and negative at 3.1 and $10.3 \mathrm{bp}$, respectively. The others exhibit greater impacts in size (17.5$27.5 \mathrm{bp}$ ) compared with those of the foreign funds rate, but they are negative. We are consistent with Lim et al. (2013) in explaining that the cash rate is a more policy-oriented target. Meanwhile, bank price-setting has been simultaneously affected by different factors at the time of cash rate shocks. In the long term, all sampled bank groups react to cash rate rises more strongly, from 111 to $115.4 \mathrm{bp}$, than they respond to rate cuts, around $81.5 \mathrm{bp}$, resulting in the positive asymmetric adjustments of their home-loan rates, which are highly consistent with the findings by Apergis and Cooray (2015). The significant Wald $F$-statistics in Panel C validate the existence of the long-run asymmetry for all groups.

Similarly, the adjustment speed to the long-run equilibrium is significantly negative for all estimates, validating the long-run association (Null Hyp. 1c). These speed magnitudes (22.4$31.7 \mathrm{bp}$ ) are much larger than those in the symmetry estimates (less than 5bp), indicating the appropriateness of the estimated methods. We also find that banks are faster to respond to cash rate shocks than to foreign funds rate changes, substantiating that the cash rate-mortgage rate movements are closely screened by the prudential authorities, politicians, and the public. Banks are under these compulsions to quickly adjust their housing rates in response to cash rate shifts.

Overall, the symmetric and asymmetric estimated results of the full sample estimates confirm our two first hypotheses: First, banks' mortgage re-pricing behaviour is significantly affected and shifted according to international funding cost developments, while the cash rate still drives mortgage interest rates. Second, heterogeneous asymmetry exists in the long-term passthrough.

\subsection{Mortgage Rate Pass-Through: Sub-sample Analysis}

We follow Apergis and Cooray (2015) in investigating the GFC effect on the asymmetric IRPT mechanism in the sub-sample analysis. Table 3 summarizes the Panel-NARDL results for the foreign funds rate-mortgage rate nexus, while Table 4 reports the cash rate estimated results. For cash rate estimates, we find only positive effects, both short- and long-term, in the preGFC period for all groups because the rates have recorded only positive changes. The magnitude of the cash rate coefficients, however, is much larger than that of the foreign-funds rate, indicating that the cash rate transmission is more effective in this period. 
[Insert Tables 3 and 4 here]

First, all error correction terms $\left(\rho_{\mathrm{i}}\right)$ are highly significant at the 1 and $5 \%$ levels and their signs are negative, reaffirming the long-run co-movements of mortgage rates and funding costs, both domestic and international. The BB estimates show a greater speed of adjustment during and after the GFC than in the pre-crisis, while the cash rate equations reveal opposite results. This outcome indicates that these banks have been quicker in adjusting their mortgage rates to the foreign funds rate shocks than to cash rate changes since the crisis. This finding signals the increasing influence of international funding costs and the decreasing effect of the cash rate in this market segment. Second, virtually all the short-term parameters of the mortgage rateforeign funds rate nexus are significantly asymmetric in the post-GFC period, while those for the GFC estimations are mostly insignificant. The upward slopes of the post-GFC estimates are all positive and much larger than the negative coefficients, revealing a positive asymmetry in line with our expectation. These results confirm our third hypothesis that, since the GFC, these mortgage lenders have been more responsive to immediate changes in the foreign funds rate than to cash rate shocks.

The long-term results in Panel A indicate some interesting differences in the responses of the banks to changes in foreign funding costs. All mortgage rates exhibit greater responsiveness (greater increases) to the cost hikes than to cost cuts (smaller decreases) during and after the crisis. The regional and sector groups are more sluggish in reducing their mortgage rates downwards in the post-crisis phase. Overall, we find all sampled banks asymmetrically adjusted their home-loan rates downwards during and after the GFC. These findings, which are consistent with Cifarelli and Paladino (2016), verify our anticipation that banks' foreign debt is a key element in explaining the misalignment of mortgage rates with the cash rate after the crisis. The key potential reason for this finding is that, due to the GFC, higher risk premiums in the money markets have induced higher funding costs for banks (Cifarelli \& Paladino, 2016; ECB, 2013). Another possible explanation, according to Apergis and Cooray (2015) and Valadkhani and Anwar (2012), is that excessive risk-taking was overestimated by the regulatory measures implemented.

For the long-term pass-through from cash rate to mortgage rates, all positive coefficients are significantly greater than the negative parameters. This result is consistent with recent studies (Valadkhani \& Worthington, 2014), which have concluded that the Big-4 are quicker to requote their lending rates in response to any cash rate rise than to any rate cut. Interestingly, we find 
smaller degrees of pass-through from cash rate reductions to mortgage rates after GFC, compared with the overshooting traverses in the crisis stage. This finding, consistent with the conclusion of Lim et al. (2013), indicates the declining effectiveness of the RBA's expansionary monetary policy. Positive traverses have been found in the pre-crisis period for all sampled groups, but there is no estimate for the negative responses in the pre-GFC period because the funds rates recorded only positive changes. In the post-crisis phase, the regional banks show sharp drops in asymmetric degrees in response to changes in both foreign funds and cash rates, while the asymmetric pricing manner remains stable among the others. This is an important finding, signifying the increasing market power of the Big-4 after the GFC.

Two key possible explanations follow. After the GFC, Australia witnessed a significant increase in bank concentration due to two bank acquisitions in 2008: CBA acquired Bankwest and St Andrew's Australia; WBC took over St. George (Australian Competition and Consumer Commission [ACCC], 2008a, 2008b). Total assets and home-loan shares of the Big-4 increased from $65.4 \%$ of total ADI assets and $74 \%$ of total residential housing loans in October 2008 (pre-mergers) to $78.5 \%$ and $90 \%$ respectively in July 2009 (post-mergers). ${ }^{9}$ As a consequence, the increased market power of the Big-4 in the GFC aftermath creates their oligopolistic competition (Khan et al., 2017), allowing them to profit from their mortgage borrowers (Davis, 2011). The collapse of the residential mortgage-backed security (RMBS) market, which provided a relatively cheap source of funding for the ADIs before the crisis, enables the four largest banks to successively take advantage of smaller banks by increasing their share of new home loans.

Our findings confirm four major conclusions: (1) the post-crisis effects of offshore bank funding costs on mortgage rates are the strongest; (2) heterogeneous asymmetries are found regarding both cash rate and international funding costs; (3) all sampled banks in the long run are more sluggish to adjust their mortgage rates downwards, resulting in the positive asymmetry; (4) the Big-4 banks are the most powerful price-makers in the mortgage market, confirming the monopolistic competition hypothesis.

\footnotetext{
${ }^{9}$ Author's calculation from APRA (2017) and ABS (2017) "Tables 9-1a and 12"
} 


\subsection{The Big-4 Asymmetric Mortgage Pricing: An Individual Analysis}

We performed eight NARDL regressions to capture the asymmetric transmission for each major bank, denoted $E R M_{1}, E R M_{2}, E R M_{3}$, and $E R M_{4}$. The general-to-specific lag selection procedure was used, starting with $p_{\max }=q_{\max }=12$, using a unidirectional $5 \%$ decision rule to select the optimal $\operatorname{NARDL}(\mathrm{p}, \mathrm{q})$ specifications. We obtained more efficient estimates and diminished noise in the dynamic multipliers by dropping all insignificant stationary regressors. The appropriateness of the NARDL model is corroborated by the significant results of the Wald $F$-statistics for long-term $\left(W_{\mathrm{LR}}\right)$ and short-run symmetries: both the impact $\left(W_{\mathrm{ISR}}\right)$ and cumulative $\left(W_{\mathrm{CSR}}\right)$. The first four columns of Table 5 reveal long-term asymmetry, whereas the following consecutive columns display short-term asymmetry and diagnostics. The bound test results, both $t_{\mathrm{TDM}}$ and $F_{\mathrm{PSS}}$, validate the presence of cointegration between mortgage rates and the foreign funds rate, but fail to confirm such a relationship with the cash rate. Most estimates pass the serial correlation test, suggesting the well-specified NARDL estimates.

\section{[Insert Table 5 here]}

The existence of asymmetry is strongly confirmed owing to the significant Wald test values, both short-term cumulative and long term. The significantly cumulative coefficients show that cash rate changes have been completely transmitted into mortgage interest rates. The positive cumulative effect is much larger than the negative, confirming the positive asymmetry or asymmetry upwards, as shown in Figure $3 \mathrm{~b}$. In the long run, all Big-4 banks react to cash rate rises more strongly, over unity, than they do to rate cuts, around $83.4 \mathrm{bp}$, except for the $E M R_{1}$ at $103.5 \mathrm{bp}$, resulting in positive asymmetric adjustments of their home-loan rates. Similar longrun positive asymmetries are found for all foreign funds rate estimates, because all positive coefficients are relatively greater than the negative coefficients. These results are consistent with the literature (Apergis \& Cooray, 2015; Valadkhani \& Anwar, 2012). The larger magnitude of the cash rate transmission shows that major banks still wield their market power to make profit by asymmetrically pricing their mortgages even the cash rate and mortgage rate movement is closely screened by the public and the legislators.

[Insert Figure 3 here]

International funding costs, nonetheless, have no contemporaneous asymmetry in major banks' mortgage pricing although the impacts still occur. Interestingly, the instant dynamics are 
greater in negative than positive changes. The cumulative Wald tests confirm that these banks respond to the foreign-funds rate in the opposite direction to the cash rate with a negative asymmetry, as shown in Figure 3a, that is similar to De Haan and Sterken's (2011) findings. Our findings indicate higher competitive pressure for banks in raising wholesale funds to finance their mortgages in the short term. These findings confirm our expectations that the international funding cost drives major lenders' mortgage rates in the short term and in the long term.

\section{Conclusions}

This paper investigates heterogeneous asymmetries in mortgage rate adjustments to changes in the cash rate and foreign funds rate for Australian banks. We apply the panel-NARDL approach to examine the novel dataset of the weekly effective interest rates on standard variable homeloans spanning the period 2002:7-2015:12.

Our analysis offers three main finding patterns. First, the results of the subsample analysis are comparatively consistent with the baseline outcomes among the four bank groups. The Big-4 banks exhibit long-term positive asymmetry in all sampled periods, and they are the most unresponsive to instantaneous shocks in both cash rate and foreign funds rate, confirming their strongest market pricing power. Second, the region group is the most responsive and are pricing followers. Third, the solid evidence of the long-term upward asymmetry has been found in both foreign funds rate and cash rate estimates.

These findings confirm that Australian banks increase their mortgage rates more significantly to respond to market rate rises and sluggishly decrease their home-loan rates in response to rate cuts. These findings imply less effectiveness for conventional monetary transmission and are therefore important to the RBA. Our findings also signify another important policy implication for the banking regulators, APRA and ACCC, in competition maintenance and consumer protection issues. The banking sector is either highly concentrated or weakly competitive because the positive asymmetry that favors mortgage lenders has been validated. This asymmetry also indicates the existence of social welfare reduction. Tacit collusion is considered as a key explanation for this phenomenon. The question here is whether the regulators should force banks to alter their mortgage rates downwards more quickly. It seems a sound idea to redistribute social welfare benefits to banks' mortgage borrowers. However, it is not practical because it is very hard to implement (De Haan \& Sterken, 2011). 
Our subsample and individual bank analyses provide several notable findings. The regional group shows interesting reactions. After the GFC, this group's mortgage rate asymmetric degrees are at the lowest level for both cash rate and foreign funds rate equations, much lower than those of the others. This suggests an increased competition in this market segment, where smaller lenders have to compete more intensely in a highly concentrated market, and reaffirms the oligopolistic feature of the Australian banking sector. This finding has major implications for the RBA and APRA in regard to their regulation and supervision of creating and maintaining adequate competition between smaller banks and larger lenders. Moreover, in the short run, mortgage lenders transmit foreign funds rate reductions into their lending prices more strongly than they transmit rate rises, contrary to their response to the cash rate, resulting in negative asymmetry. Finally, the post-crisis effects of foreign funding costs on mortgage rates are stronger than the pre-crisis and GFC influences. We also confirm the impairment of cash rate transmission after the crisis. This is consistent with the reviewed literature finding that policy transmission after the GFC has been unable to reduce the bank markups charged over funding costs. Our finding suggests important reforms are needed in the RBA monetary policy. 


\section{Acknowledgements}

The authors greatly appreciate the constructive feedback that the journal editor and anonymous referees have provided. It has enabled us to make significant improvements to our paper. We are also grateful for the helpful comments made by the participants at the Financial Planning and Investment Symposium, November 2014 at Flinders University; the Personal Finance and Investment Symposium (PFIS), November 2015 at Griffith University; the Australasian Housing Researchers Conference (AHRC), February 2015 at University of Tasmania; the Accounting and Finance Doctoral Symposium (AFAANZ), 30June-1July 2016, Gold Coast; the Asia-Pacific Network for Housing Research, December 2016 at Sun Yat-sen University, Guangzhou; and particularly the Griffith seminar participants at the $\mathrm{PhD}$ Brown Bag on Corporate Governance and Financial Markets on 2 December 2015; and the PhD Student Symposium on 25 February 2016. The authors thank Robert Faff and Henk Berkman, reviewers of the 2016 AFAANZ. We thank Griffith University Postgraduate Student Association (GUPSA) for their English editing service.

\section{Funding}

This work was supported by the Vietnamese Government, Project 165 and the Australian Centre of Financial Studies through a research grant (2015).

\section{Data and Computer Code Availability}

The data that support the findings of this study are available from CANNEX but restrictions apply to the availability of these data, which were used under license for the current study, and so are not publicly available. Instructions for how other researchers can obtain the data and all the information needed to proceed from the raw data to the results of the paper (including codes) are, however, available from the authors upon reasonable request and with permission of CANNEX. 


\section{References}

ABC. (2017). Australian mortage debt to GDP 1860-2016. Retrieved April 24, 2017, from http://www.abc.net.au/news/2017-04-09/mortgage-toaustralian-gdp-ration/8429174

ACCC. (2008a). Public competition assessment: Commonwealth Bank of Australia proposed acquisition of Bankwest and St Andrew's Australia.

ACCC. (2008b). Public competition assessment: Westpac Banking Corporation proposed acquisition of St George Bank Limited.

Allen, J., \& McVanel, D. (2009). Price movements in the Canadian residential mortgage market. Bank of Canada Working Paper, 13/2009.

Apergis, N., \& Cooray, A. (2015). Asymmetric interest rate pass-through in the U.S., the U.K. and Australia: New evidence from selected individual banks. Journal of Macroeconomics, 45, 155-172. https://doi.org/10.1016/j.jmacro.2015.04.010

APRA. (2017). Monthly banking statistics. Retrieved January 5, 2017, from http://www.apra.gov.au/adi/Publications/Pages/monthly-bankingstatistics.aspx

Aristei, D., \& Gallo, M. (2014). Interest rate pass-through in the Euro area during the financial crisis: A multivariate regime-switching approach. Journal of Policy Modeling, 36, 273-295. https://doi.org/10.1016/j.jpolmod.2013.12.002

Atil, A., Lahiani, A., \& Nguyen, D. K. (2014). Asymmetric and nonlinear passthrough of crude oil prices to gasoline and natural gas prices. Energy Policy, 65, 567-573. https://doi.org/10.1016/j.enpol.2013.09.064

Australian Bureau of Statistics (ABS). (2017). Australian National Accounts: Housing Finance, May 2017 (5609.0). Canberra.

Baglioni, A. (2007). Monetary policy transmission under different banking 
structures: The role of capital and heterogeneity. International Review of Economics \& Finance, 16(1), 78-100. https://doi.org/10.1016/J.IREF.2005.04.002

Bailey, O., Uffelen, L. Van, \& Wood, K. (2012). International activities of Australian banks. RBA Monthly Bulletin, (December), 47-56.

Banerjee, A., Dolado, J., \& Mestre, R. (1998). Error-correction mechanism tests for cointegration in a single-equation framework. Journal of Time Series Analysis, 19(3), 267-283. https://doi.org/10.1111/1467-9892.00091

Barrell, R., Costantini, M., \& Meco, I. (2015). Housing wealth, financial wealth, and consumption: New evidence for Italy and the UK. International Review of Financial Analysis, 42, 316-323. https://doi.org/10.1016/j.irfa.2015.08.007

Becker, R., Osborn, D. R., \& Yildirim, D. (2012). A threshold cointegration analysis of interest rate pass-through to UK mortgage rates. Economic Modelling, 29(6), 2504-2513. https://doi.org/10.1016/j.econmod.2012.08.004

Belke, A., Beckmann, J., \& Verheyen, F. (2013). Interest rate pass-through in the EMU - New evidence from nonlinear cointegration techniques for fully harmonized data. Journal of International Money and Finance. https://doi.org/10.1016/j.jimonfin.2013.05.006

Breitung, J. (2015). "The local power of some unit root tests for panel data" In Nonstationary Panels, Panel Cointegration, and Dynamic Panels. (Nonstation).

Calza, A., \& Stracca, L. (2013). Housing finance and monetary policy. Journal of the European Economic Association, 11(S1), 101-122.

Campbell, J. Y., \& Cocco, J. F. (2007). How do house prices affect consumption? Evidence from micro data. Journal of Monetary Economics, 54(3), 591-621. https://doi.org/10.1016/j.jmoneco.2005.10.016

Cifarelli, G., \& Paladino, G. (2016). Time-varying mark-up and the ECB monetary policy transmission in a highly non linear framework. International Review of Economics \& Finance, 45, 247-262. 
https://doi.org/10.1016/j.iref.2016.06.001

Commins, P. (2014). Property makes Australians the world's richest, says Credit Suisse. The Sydney Morning Herald. Sydney.

Corvoisier, S., \& Gropp, R. (2002). Bank concentration and retail interest rates. Journal of Banking and Finance, 26(11), 2155-2189. https://doi.org/10.1016/S0378-4266(02)00204-2

Davis, K. (2011). The Australian financial system in the 2000s: Dodging the bullet. In RBA Annual Conference - 2011 The Australian Economy in the 2000s (pp. 301-348). Sydney.

De Bondt, G. J. (2005). Interest rate pass-through: Empirical results for the Euro area. German Economic Review, 6(1), 37-78. https://doi.org/10.1111/j.1465-6485.2005.00121.x

De Graeve, F., De Jonghe, O., \& Vennet, R. Vander. (2007). Competition, transmission and bank pricing policies: Evidence from Belgian loan and deposit markets. Journal of Banking \& Finance, 31(1), 259-278. https://doi.org/10.1016/j.jbankfin.2006.03.003

De Haan, L., \& Sterken, E. (2011). Bank-specific daily interest rate adjustment in the Dutch mortgage market. Journal of Financial Services Research, 39(3), 145-159. https://doi.org/10.1007/s10693-010-0095-2

Deans, C., \& Stewart, C. (2012). Banks ' funding costs and lending rates. $R B A$ Monthly Bulletin, (March), 37-43.

ECB. (2013). Articles assessing the retail bank interest rate pass-through in the euro area at times of financial fragmentation. ECB Monthly Bulletin, (August), 75-91.

Elbourne, A. (2008). The UK housing market and the monetary policy transmission mechanism: An SVAR approach. Journal of Housing Economics, 17(1), 65-87. https://doi.org/10.1016/j.jhe.2007.09.002

Farr, M. (2016, August 4). Bill Shorten says PM Malcolm Turnbull is "weak" on 
banks failing to pass on full rate cut. News Corp Australia Network. Sydnety.

Fousekis, P., Katrakilidis, C., \& Trachanas, E. (2016). Vertical price transmission in the US beef sector: Evidence from the nonlinear ARDL model. Economic Modelling, 52, 499-506. https://doi.org/10.1016/j.econmod.2015.09.030

Freixas, X., \& Rochet, J.-C. (2008). Microeconomics of Banking (2nd ed.). Cambridge: MIT Press.

Fuertes, A., Heffernan, S., \& Kalotychou, E. (2010). How do UK banks react to changing central bank rates? Journal of Financial Services Research, 37(2), 99-130. https://doi.org/10.1007/s10693-009-0056-9

Fuster, A., \& Vickery, J. (2015). Securitization and the fixed-rate mortgage. Review of Financial Studies, 28(1), 176-211. https://doi.org/10.1093/rfs/hhu060

Gambacorta, L. (2008). How do banks set interest rates? European Economic Review, 52(5), 792-819. https://doi.org/10.1016/j.euroecorev.2007.06.022 Granger, C. W., \& Yoon, G. (2002). Hidden Cointegration. University of California, 2002-2, 1-48.

Guttmann, R., \& Rodgers, D. (2015). International banking and liquidity risk transmission: Evidence from Australia. IMF Economic Review, 63(3), 411425. https://doi.org/10.1057/imfer.2015.27

Hadri, K. (2000). Testing for stationarity in heterogenous panel data. The Econometrics Journal, 3(2), 148-161. https://doi.org/10.1111/1368423X.00043

Hannan, T. H., \& Berger, A. N. (1991). The rigidity of prices: Evidence from the banking industry. The American Economic Review, 81(4), 938-945.

Harris, R. D. F., \& Tzavalis, E. (1999). Inference for unit roots in dynamic panels where the time dimension is fixed. Journal of Econometrics, 91(2), 201-226. https://doi.org/10.1016/S0304-4076(98)00076-1

Hristov, N., Hülsewig, O., \& Wollmershäuser, T. (2014). The interest rate passthrough in the Euro area during the global financial crisis. Journal of Banking 
\& Finance, 48, 104-119. https://doi.org/10.1016/j.jbankfin.2014.08.004 Iacoviello, M., \& Minetti, R. (2008). The credit channel of monetary policy: Evidence from the housing market. Journal of Macroeconomics, 30(1), 69-96. https://doi.org/10.1016/j.jmacro.2006.12.001

Illes, A., Lombardi, M. J., \& Mizen, P. (2015). Why did bank lending rates diverge from policy rates after the financial crisis? BIS Working Papers, 486.

Im, K. S., Pesaran, M. H., \& Shin, Y. (2003). Testing for unit roots in heterogeneous panels. Journal of Econometrics, 115(1), 53-74. https://doi.org/10.1016/S0304-4076(03)00092-7

IMF. (2012). Australia: Addressing systemic risk through higher loss absorbencyTechnical note. IMF Country Report no. 12/311, IMF, Washington DC, 7. IMF. (2017). Financial soundness indicators. Retrieved April 24, 2017, from http://data.imf.org/?sk=51B096FA-2CD2-40C2-8D09-0699CC1764DA Janda, M. (2016, August 2). Interest rates slashed to record low of 1.5pc by Reserve Bank, banks pass on half. Retrieved December 5, 2016, from http://www.abc.net.au/news/2016-08-02/reserve-bank-cuts-interestrates $/ 7682170$

Khan, H. H., Kutan, A. M., Ahmad, R. B., \& Gee, C. S. (2017). Does higher bank concentration reduce the level of competition in the banking industry? Further evidence from South East Asian economies. International Review of Economics and Finance, 52(April), 91-106. https://doi.org/10.1016/j.iref.2017.09.006

Kusher, C. (2015). Australian mortgage holders sensitive to interest rate movements. CoreLogic.

Kwapil, C., \& Scharler, J. (2013). Expected monetary policy and the dynamics of bank lending rates. International Review of Economics \& Finance, 27, 542551. https://doi.org/10.1016/J.IREF.2013.01.010

Lawless, T. (2016). Quarterly Housing \& Economic Review - December 2016 
release. CoreLogic.

Levin, A., Lin, C. F., \& Chu, C. S. J. (2002). Unit root tests in panel data: Asymptotic and finite-sample properties. Journal of Econometrics, 108, 1-24. https://doi.org/10.1016/S0304-4076(01)00098-7

Lim, G. C., Tsiaplias, S., \& Chua, C. L. (2013). Bank and official interest rates: How do they interact over time? Economic Record, 89(285), 160-174. https://doi.org/10.1111/1475-4932.12030

Liu, M.-H., Margaritis, D., \& Tourani-Rad, A. (2011). Asymmetric information and price competition in small business lending. Journal of Banking \& Finance, 35(9), 2189-2196. https://doi.org/10.1016/j.jbankfin.2011.01.022

Long, S., Sales, L., \& Puccini, J. (2011). Banks quiet on rates cut. 7.30. Australia. Lowe, P., \& Rohling, T. (1992). Loan rate stickiness: theory and evidence. Research Discussion Paper 9206, Reserve Bank of Australia.

Maddala, G. S., \& Wu, S. (1999). A comparative study of unit root tests with panel data and a new simple test. Oxford Bulletin of Economics and Statistics, 61(S1), 631-652.

McIlroy, T. (2016, August 3). Malcolm Turnbull calls on bank bosses to pass on interest rate cut. The Sydney Morning Herald. Sydney.

Milcheva, S., \& Sebastian, S. (2016). The housing market channel of monetary policy transmission in the euro area. Journal of European Real Estate Research, 9(1), 76-97.

Musso, A., Neri, S., \& Stracca, L. (2011). Housing, consumption and monetary policy: How different are the US and the euro area? Journal of Banking and Finance, 35(11), 3019-3041. https://doi.org/10.1016/j.jbankfin.2011.04.004

Navarro, M. L., \& de Frutos, R. F. (2015). Residential versus financial wealth effects on consumption from a shock in interest rates. Economic Modelling, 49, 81-90. https://doi.org/10.1016/j.econmod.2015.03.016 
Neumark, D., \& Sharpe, S. A. (1992). Market structure and the nature of price rigidity: Evidence from the market for consumer deposits. The Quarterly Journal of Economics, 107(2), 657-680.

Payne, J. E. (2006). The response of the conventional mortgage rate to the federal funds rate: Symmetric or asymmetric adjustment? Applied Financial Economics Letters, 2(5), 279-284. https://doi.org/10.1080/17446540600647037

Payne, J. E. (2007). Interest rate pass through and asymmetries in adjustable rate mortgages. Applied Financial Economics, 17(17), 1369-1376. https://doi.org/10.1080/09603100601018872

Peltonen, T. A., Sousa, R. M., \& Vansteenkiste, I. S. (2012). Wealth effects in emerging market economies. International Review of Economics and Finance, 24, 155-166. https://doi.org/10.1016/j.iref.2012.01.006

Pesaran, M. H. (2007). A simple panel unit root test in the presence of crosssection dependence. Journal of Applied Econometrics, 22(2), 265-312. https://doi.org/10.1002/jae.951

Pesaran, M. H., Shin, Y., \& Smith, R. J. (2001). Bounds testing approaches to the analysis of level relationships. Journal of Applied Econometrics, 16, 289-326. https://doi.org/10.1002/jae.616

Pesaran, M. H., Shin, Y., \& Smith, R. P. (1999). Pooled mean group estimation of dynamic heterogeneous panels. Journal of the American Statistical Association, 94(446), 621-634.

Pesaran, M. H., \& Smith, R. (1995). Estimating long-run relationships from dynamic heterogeneous panels. Journal of Econometrics, 68, 79-113. https://doi.org/10.1016/0304-4076(94)01644-F

Ralston, D., \& Davis, K. (2011). The future of Australian bank funding. RBA. (2006). Australian banks' global bond funding. RBA Monthly Bulletin, (August), 1-6. 
Reserve Bank of Australia (RBA). (2017). Statistics tables. Retrieved February 22, 2017, from http://www.rba.gov.au/statistics/tables/

Rousseas, S. (1985). A markup theory of bank loan rates. Journal of Post Keynesian Economics, 8(1), 135-144.

https://doi.org/10.1080/01603477.1985.11489549

Sander, H., \& Kleimeier, S. (2004). Convergence in euro-zone retail banking? What interest rate pass-through tells us about monetary policy transmission, competition and integration. Journal of International Money and Finance, 23(3), 461-492. https://doi.org/10.1016/j.jimonfin.2004.02.001

Shin, Y., Yu, B., \& Greenwood-Nimmo, M. (2014). Modelling Asymmetric Cointegration and Dynamic Multipliers in a Nonlinear ARDL Framework. (R. C. Sickles \& W. C. Horrace, Eds.), Festschrift in Honor of Peter Schmidt: Econometric Methods and Applications. New York: Springer New York. https://doi.org/10.1007/978-1-4899-8008-3_9

Stewart, C., Robertson, B., \& Alexandra, H. (2013). Trends in the funding and lending behaviour of Australian banks. Research Discussion Paper 2013/15, Reserve Bank of Australia.

Stiglitz, J. E., \& Weiss, A. (1981). Credit rationing in markets with imperfect information. The American Economic Review, 71(3), 393-410.

Toolsema, L. A., \& Jacobs, J. P. A. M. (2007). Why do prices rise faster than they fall? With an application to mortgage rates. Managerial and Decision Economics, 28(7), 701-712. https://doi.org/10.1002/mde.1382

Turner, G., \& Nugent, J. (2015). International linkages of the Australian banking system : Implications for financial stability. The Finsia Journal of Applied Finance, (3), 34-43.

Valadkhani, A. (2013). The pricing behaviour of Australian banks and building societies in the residential mortgage market. Journal of International Financial Markets, Institutions and Money, 26(1), 133-151. https://doi.org/10.1016/j.intfin.2013.05.003 
Valadkhani, A., \& Anwar, S. (2012). Interest rate pass-through and the asymmetric relationship between the cash rate and the mortgage rate. Economic Record, 88(282), 341-350. https://doi.org/10.1111/j.14754932.2012.00823.x

Valadkhani, A., \& Worthington, A. (2014). Asymmetric behavior of Australia's Big-4 banks in the mortgage market. Economic Modelling, 43, 57-66. https://doi.org/10.1016/j.econmod.2014.07.044

Van Leuvensteijn, M., Kok Sørensen, C., Bikker, J. A., \& Van Rixtel, A. A. R. J. M. (2013). Impact of bank competition on the interest rate pass- through in the euro area. Applied Economics, 45(11), 1359-1380. https://doi.org/10.1080/00036846.2011.617697

Von Borstel, J., Eickmeier, S., \& Krippner, L. (2016). The interest rate passthrough in the Euro area during the sovereign debt crisis. Journal of International Money and Finance, 68, 386-402. https://doi.org/10.1016/j.jimonfin.2016.02.014

Wilkins, K., Gardner, G., \& Chapman, B. (2016). Developments in banks ' funding costs and lending rates. RBA Monthly Bulletin, (March), 21-30.

Yeates, C. (2016, August 2). Banks fail to pass on full RBA rate cut. The Sydney Morning Herald. Sydney.

Yeates, C. (2017, January 27). Bank funding costs tipped to rise this year. The Age. 


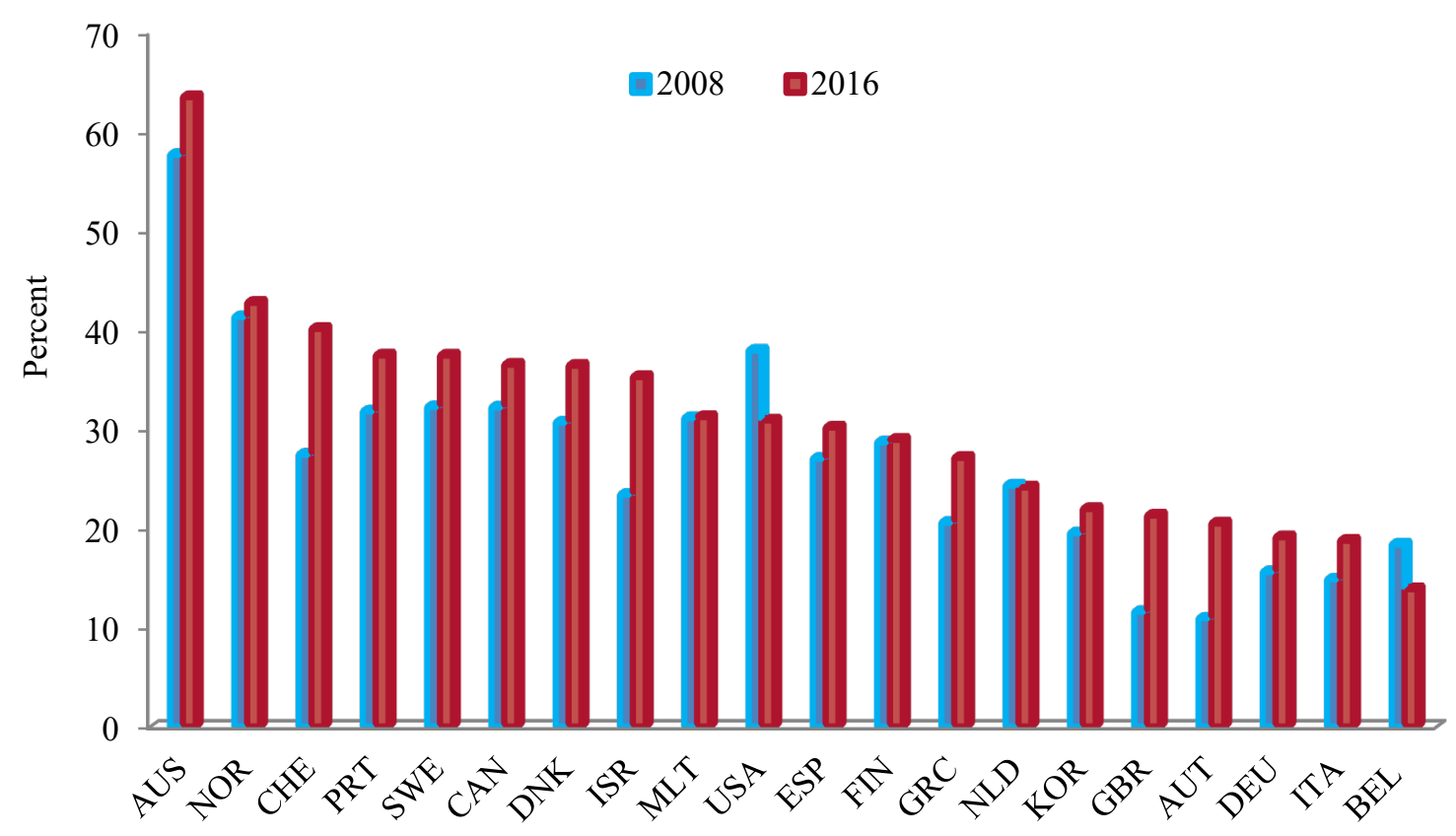

Figure 1. Residential mortgages as a share of total bank loans in selected OECD markets. Source: IMF 2017 , Financial Soundness Indicators Database. Data is as of December 2016 or latest available. 


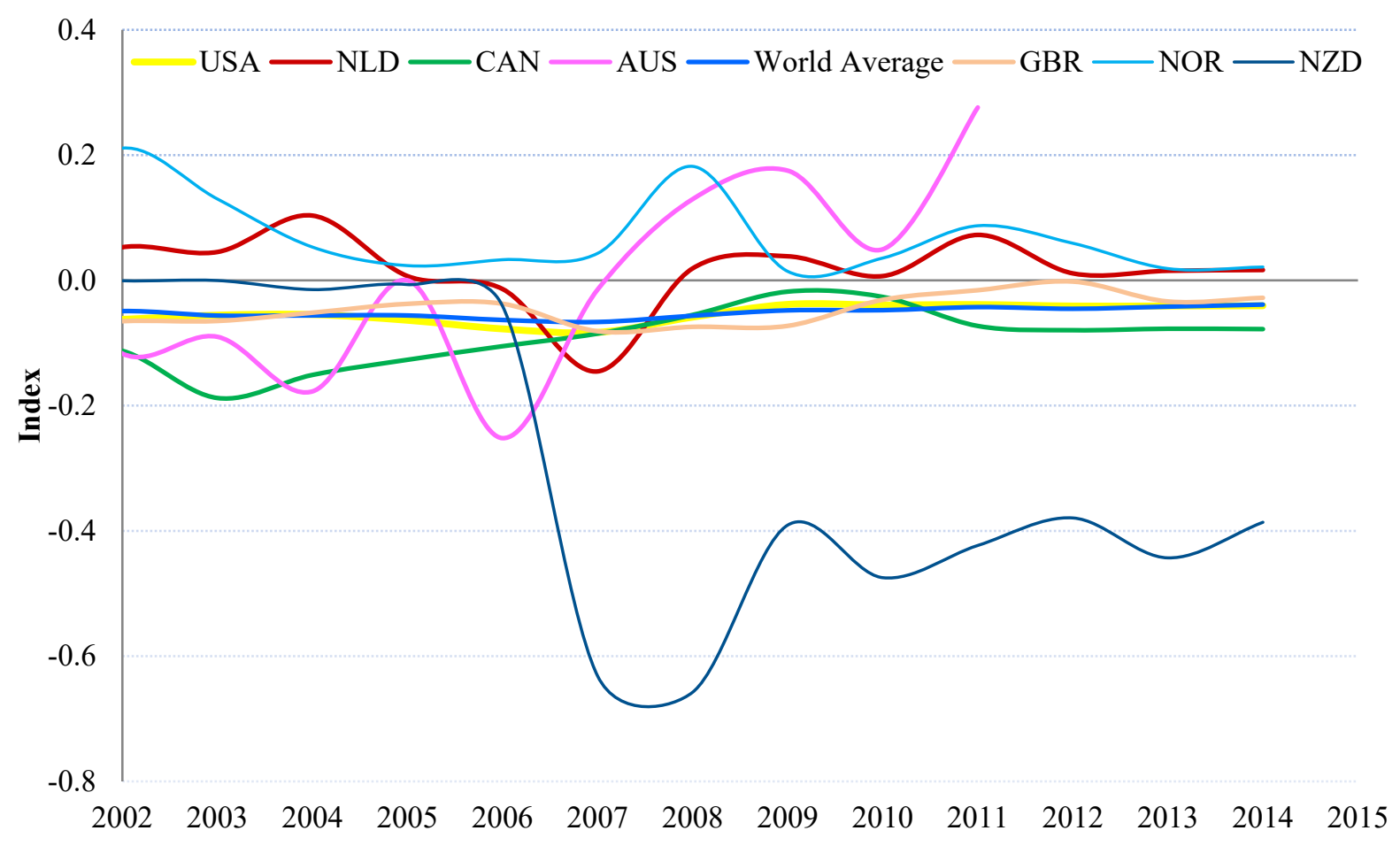

Figure 2. Boone Indicators in Banking markets for selected OECD countries. Source: World Bank (2017), Boone Indicator in Banking Markets Database. Data is as of December 2016 or latest available, retrieved from FRED, Federal Reserve Bank of St. Louis; https://fred.stlouisfed.org/series/DDOI05AUA156NWDB 
Table 1

Baseline Mortgage Rate Pass-Through Results Using $B B$

\begin{tabular}{|c|c|c|c|c|}
\hline Variables & Sector & Foreign & Major & Region \\
\hline \multicolumn{5}{|c|}{ A: Models without asymmetry } \\
\hline \multirow[t]{2}{*}{$L_{B B}(\beta)$} & $0.708^{* * *}$ & $0.687^{* * *}$ & $0.684^{* * *}$ & $0.721^{* * *}$ \\
\hline & $(0.015)$ & $(0.049)$ & $(0.030)$ & $(0.023)$ \\
\hline \multirow[t]{2}{*}{ Constant $(\mu)$} & $0.150^{* * *}$ & $0.108^{* * *}$ & $0.136^{* * *}$ & $0.164^{* * *}$ \\
\hline & $(0.011)$ & $(0.017)$ & $(0.009)$ & $(0.014)$ \\
\hline \multirow{2}{*}{$\rho$} & $-0.043^{* * *}$ & $-0.027^{* * *}$ & $-0.035^{* * *}$ & $-0.048^{* * *}$ \\
\hline & $(0.005)$ & $(0.005)$ & $(0.002)$ & $(0.007)$ \\
\hline \multirow{2}{*}{$\Delta B B\left(\pi_{i, 0}\right)$} & $0.204^{* * *}$ & $0.198^{* * *}$ & $0.234^{* * *}$ & $0.197^{* * *}$ \\
\hline & $(0.019)$ & $(0.008)$ & $(0.060)$ & $(0.024)$ \\
\hline \multirow{2}{*}{$\begin{array}{l}\text { Hausman test } \\
\chi_{k}^{2} \text { Prob] }\end{array}$} & 126.97 & 0.010 & 0.000 & 16.710 \\
\hline & {$[0.000]$} & [0.919] & {$[0.990]$} & {$[0.000]$} \\
\hline Obs. & 13,795 & 2,115 & 2,820 & 8,860 \\
\hline \multicolumn{5}{|c|}{ B: Models with asymmetry } \\
\hline \multirow[t]{2}{*}{$L_{B B}^{+}$} & $0.932^{* * *}$ & $0.946^{* * *}$ & $0.941^{* * *}$ & $0.926^{* * *}$ \\
\hline & $(0.005)$ & $(0.014)$ & $(0.011)$ & $(0.006)$ \\
\hline \multirow{2}{*}{$L_{B B}^{-}$} & $0.840^{* * *}$ & $0.843^{* * *}$ & $0.852^{* * *}$ & $0.835^{* * *}$ \\
\hline & $(0.004)$ & $(0.012)$ & $(0.009)$ & $(0.005)$ \\
\hline $\mathrm{D}_{(L \mp)}$ & 0.092 & 0.103 & 0.089 & 0.091 \\
\hline \multirow[t]{2}{*}{ Constant $\left(\mu_{i}\right)$} & $0.910^{* * *}$ & $0.875^{* * *}$ & $0.997^{* * *}$ & $0.909^{* * *}$ \\
\hline & $(0.085)$ & $(0.178)$ & $(0.053)$ & $(0.125)$ \\
\hline \multirow{2}{*}{$\rho_{i}$} & $-0.139^{* * *}$ & $-0.133^{* * *}$ & $-0.151^{* * *}$ & $-0.139^{* * *}$ \\
\hline & $(0.013)$ & $(0.029)$ & $(0.0089)$ & $(0.019)$ \\
\hline \multirow[t]{2}{*}{$\Delta B B_{0}^{+}=\pi_{i, 0}^{+}$} & $0.041^{* *}$ & $0.086^{* *}$ & $0.027^{* * *}$ & 0.033 \\
\hline & $(0.017)$ & $(0.043)$ & $(0.010)$ & $(0.024)$ \\
\hline \multirow[t]{2}{*}{$\Delta B B_{0}^{-}=\pi_{i, 0}^{-}$} & $0.089^{* * *}$ & 0.024 & $0.204^{* * *}$ & 0.064 \\
\hline & $(0.033)$ & $(0.053)$ & $(0.047)$ & $(0.045)$ \\
\hline \multicolumn{5}{|l|}{ C: Diagnostics } \\
\hline \multirow[t]{2}{*}{$W_{\mathrm{LR}} H_{0}: \beta^{+}=\beta^{-}$} & $7.28 \mathrm{E}+03$ & $1.14 \mathrm{E}+03$ & $1.45 \mathrm{E}+03$ & $4.89 \mathrm{E}+03$ \\
\hline & {$[0.000]$} & {$[0.000]$} & {$[0.000]$} & {$[0.000]$} \\
\hline \multirow{2}{*}{$W_{\text {ISR }} H_{0}: \pi_{0}^{+}=\pi_{0}^{-}$} & $1.69 \mathrm{E}+03$ & $5.40 \mathrm{E}-01$ & $9.73 \mathrm{E}+03$ & 4.40E-01 \\
\hline & {$[0.193]$} & {$[0.463]$} & {$[0.002]$} & {$[0.508]$} \\
\hline \multirow{3}{*}{$\begin{array}{l}\text { Hausman test } \\
\chi_{k}^{2}[\text { Prob }] \\
\text { Obs. }\end{array}$} & 0.100 & 0.420 & 0.050 & 0.010 \\
\hline & [0.952] & [0.811] & {$[0.975]$} & [0.994] \\
\hline & 13,795 & 2,115 & 2,820 & 8,860 \\
\hline
\end{tabular}

Notes: $L_{\mathrm{BB}}$ is the long-run effect of the international funding cost on mortgage rates (in italics if equal unity). $L_{B B}^{+}$and $L_{B B}^{-}$denote the asymmetric long-run coefficients, defined by $\beta_{i}^{+}=-\delta_{i}^{+} / \rho_{i}$ and $\beta_{i}^{-}=$ $-\delta_{i}^{-} / \rho_{i}$, respectively. $\Delta B B_{0}^{+}$and $\Delta B B_{0}^{-}$refer to asymmetric impacts associated with instant positive and negative shocks in $B B . W_{\mathrm{LR}}$ and $W_{\mathrm{ISR}}$ represent the Wald statistics for the equality of long- and short-run parameters. Standard errors and p-values are given in brackets and parentheses. 
Table 2

Baseline Mortgage Rate Pass-Through Results Using $C R$

\begin{tabular}{|c|c|c|c|c|}
\hline Variables & Sector & Foreign & Major & Region \\
\hline \multicolumn{5}{|c|}{ A: Models without asymmetry } \\
\hline \multirow[t]{2}{*}{$L_{C R}(\beta)$} & $0.755^{* * *}$ & $0.676^{* * *}$ & $0.693^{* * *}$ & $0.732^{* * *}$ \\
\hline & $(0.015)$ & $(0.044)$ & $(0.031)$ & $(0.027)$ \\
\hline \multirow[t]{2}{*}{ Constant $(\mu)$} & $0.142^{* * *}$ & $0.126^{* * *}$ & $0.134^{* * *}$ & $0.177^{* * *}$ \\
\hline & $(0.016)$ & $(0.021)$ & $(0.037)$ & $(0.016)$ \\
\hline \multirow[t]{2}{*}{$\rho$} & $-0.039^{* * *}$ & $-0.030^{* * *}$ & $-0.033^{* * *}$ & $-0.051^{* * *}$ \\
\hline & $(0.005)$ & $(0.006)$ & $(0.009)$ & $(0.008)$ \\
\hline \multirow[t]{2}{*}{$\Delta C R\left(\pi_{i, 0}\right)$} & 0.041 & $-0.027^{* * *}$ & 0.185 & 0.004 \\
\hline & $(0.042)$ & $(0.007)$ & $(0.187)$ & $(0.028)$ \\
\hline \multirow{2}{*}{$\begin{array}{l}\text { Hausman test } \\
\chi_{k}^{2}[\text { Prob }]\end{array}$} & 2.190 & 0.100 & 1.000 & 9.220 \\
\hline & [0.139] & {$[0.754]$} & {$[0.317]$} & {$[0.002]$} \\
\hline Observations & 13,795 & 2,115 & 2,820 & 8,860 \\
\hline \multicolumn{5}{|c|}{ B: Models with asymmetry } \\
\hline \multirow{2}{*}{$L_{C R}^{+}$} & $1.123^{* * *}$ & $1.154^{* * *}$ & $1.110^{* * *}$ & $1.125^{* * *}$ \\
\hline & $(0.003)$ & $(0.010)$ & $(0.006)$ & $(0.004)$ \\
\hline \multirow{2}{*}{$L_{C R}^{-}$} & $0.815^{* * *}$ & $0.818^{* * *}$ & $0.816^{* * *}$ & $0.812^{* * *}$ \\
\hline & $(0.002)$ & $(0.006)$ & $(0.004)$ & $(0.003)$ \\
\hline $\mathrm{D}_{(L \mp)}$ & 0.308 & 0.336 & 0.294 & 0.313 \\
\hline \multirow{2}{*}{ Constant $\left(\mu_{i}\right)$} & $1.561^{* * *}$ & $1.459^{* * *}$ & $2.089^{* * *}$ & $1.463^{* * *}$ \\
\hline & $(0.187)$ & $(0.449)$ & $(0.404)$ & $(0.241)$ \\
\hline \multirow[t]{2}{*}{$\rho_{i}$} & $-0.239^{* * * *}$ & $-0.224^{* * *}$ & $-0.317^{* * *}$ & $-0.225^{* * *}$ \\
\hline & $(0.029)$ & $(0.072)$ & $(0.061)$ & $(0.037)$ \\
\hline \multirow{2}{*}{$\Delta C R_{0}^{+}=\pi_{i, 0}^{+}$} & $-0.175^{* * *}$ & $-0.275^{* * *}$ & -0.0313 & $-0.204^{* * *}$ \\
\hline & $(0.059)$ & $(0.104)$ & $(0.269)$ & $(0.043)$ \\
\hline \multirow{2}{*}{$\Delta C R_{0}^{-}=\pi_{i, 0}^{-}$} & $-0.170^{* * * *}$ & $-0.213^{* * *}$ & -0.103 & $-0.187^{* * *}$ \\
\hline & $(0.045)$ & $(0.063)$ & $(0.221)$ & $(0.029)$ \\
\hline \multicolumn{5}{|l|}{ C: Diagnostics } \\
\hline \multirow[t]{2}{*}{$W_{\mathrm{LR}} H_{0}: \beta^{+}=\beta^{-}$} & $3.03 \mathrm{E}+04$ & $4.56 \mathrm{E}+03$ & $1.01 \mathrm{E}+04$ & $1.74 \mathrm{E}+04$ \\
\hline & {$[0.000]$} & {$[0.000]$} & {$[0.000]$} & {$[0.000]$} \\
\hline \multirow[t]{2}{*}{$W_{\text {ISR }} H_{0}: \pi_{0}^{+}=\pi_{0}^{-}$} & 0.040 & 1.910 & 2.250 & 0.580 \\
\hline & [0.836] & {$[0.167]$} & [0.133] & [0.445] \\
\hline \multirow{3}{*}{$\begin{array}{l}\text { Hausman test } \\
\chi_{k}^{2}[\text { Prob }] \\
\text { Observations }\end{array}$} & 0.750 & 0.910 & 0.540 & 2.000 \\
\hline & [0.686] & {$[0.634]$} & [0.764] & [0.368] \\
\hline & 13,795 & 2,115 & 2,820 & 8,860 \\
\hline
\end{tabular}

Notes: $L_{\mathrm{CR}}$ indicates the long-run effect of the cash rate on mortgage rates. $L_{\mathrm{CR}}^{+}$and $L_{\mathrm{CR}}^{-}$denote the asymmetric long-run coefficients associated with cash rate rises and cuts respectively. $\triangle C R_{0}^{+}$and $\triangle C R_{0}^{-}$ represent instant asymmetric impacts at the time cash rate shock. The remainder are similar to Table 3 . 
Table 3

Sub-analysis Pass-Through Results Using $B B$

\begin{tabular}{|c|c|c|c|c|c|c|c|c|c|c|c|c|}
\hline \multirow{2}{*}{ Variables } & \multicolumn{3}{|c|}{ Sector } & \multicolumn{3}{|c|}{ Foreign } & \multicolumn{3}{|c|}{ Major } & \multicolumn{3}{|c|}{ Region } \\
\hline & Pre-GFC & GFC & Post-GFC & Pre-GFC & GFC & Post-GFC & Pre-GFC & GFC & Post-GFC & Pre-GFC & GFC & Post-GFC \\
\hline \multicolumn{13}{|c|}{ A: Long run } \\
\hline \multirow[t]{2}{*}{$L_{B B}^{+}$} & $0.911^{* * *}$ & $0.996^{* * *}$ & $0.998^{* * *}$ & $0.900^{* * *}$ & $1.025^{* * *}$ & $1.044^{* * *}$ & $0.815^{* * *}$ & $1.003^{* * *}$ & $1.001^{* * *}$ & $0.943^{* * *}$ & $0.989^{* * *}$ & $0.985^{* * *}$ \\
\hline & $(0.055)$ & $(0.021)$ & $(0.020)$ & $(0.027)$ & $(0.060)$ & $(0.046)$ & $(0.007)$ & $(0.046)$ & $(0.045)$ & $(0.084)$ & $(0.026)$ & $(0.025)$ \\
\hline \multirow[t]{2}{*}{$L_{B B}^{-}$} & $0.872^{* * *}$ & $0.854^{* * *}$ & $0.897^{* * *}$ & $0.845^{* * *}$ & $0.852^{* * *}$ & $0.920^{* * *}$ & $0.721^{* * *}$ & $0.864^{* * *}$ & $0.916^{* * *}$ & $0.925^{* * *}$ & $0.852^{* * *}$ & $0.885^{* * *}$ \\
\hline & $(0.106)$ & $(0.010)$ & $(0.012)$ & $(0.039)$ & $(0.029)$ & $(0.028)$ & $(0.002)$ & $(0.022)$ & $(0.027)$ & $(0.163)$ & $(0.012)$ & $(0.015)$ \\
\hline $\mathrm{D}_{(L \mp)}$ & 0.039 & 0.142 & 0.101 & 0.055 & 0.173 & 0.124 & 0.094 & 0.139 & 0.085 & 0.018 & 0.137 & 0.100 \\
\hline \multirow{2}{*}{$\mu_{i}$} & $1.184^{* * *}$ & $1.334^{* * *}$ & $0.690^{* * *}$ & $0.972^{* * *}$ & $1.198^{* * *}$ & $0.787^{* * *}$ & $1.218^{* * *}$ & $1.365^{* * *}$ & $0.719^{* * *}$ & $1.222^{* * *}$ & $1.363^{* * *}$ & $0.665^{* * *}$ \\
\hline & $(0.073)$ & $(0.040)$ & $(0.065)$ & $(0.278)$ & $(0.136)$ & $(0.059)$ & $(0.079)$ & $(0.055)$ & $(0.123)$ & $(0.092)$ & $(0.049)$ & $(0.098)$ \\
\hline \multicolumn{13}{|c|}{ B: Short run } \\
\hline \multirow[t]{2}{*}{$\rho_{i}$} & $-0.178^{* * *}$ & $-0.218^{* * *}$ & $-0.107^{* * *}$ & $-0.146^{* * *}$ & $-0.200^{* * *}$ & $-0.122^{* * *}$ & $-0.181^{* * *}$ & $-0.221^{* * *}$ & $-0.108^{* * *}$ & $-0.184^{* * *}$ & $-0.223^{* * *}$ & $-0.104^{* * *}$ \\
\hline & $(0.012)$ & $(0.007)$ & $(0.010)$ & $(0.042)$ & $(0.024)$ & $(0.008)$ & $(0.010)$ & $(0.010)$ & $(0.018)$ & $(0.015)$ & $(0.008)$ & $(0.015)$ \\
\hline \multirow[t]{2}{*}{$\Delta B B_{0}^{+}$} & $0.076^{* *}$ & -0.003 & $0.163^{* * *}$ & 0.001 & 0.057 & $0.142^{* * *}$ & $0.039^{* *}$ & $-0.067^{* * *}$ & $0.173^{* * *}$ & $0.129^{* * *}$ & 0.003 & $0.163^{* * *}$ \\
\hline & $(0.032)$ & $(0.021)$ & $(0.017)$ & $(0.157)$ & $(0.041)$ & $(0.005)$ & $(0.018)$ & $(0.023)$ & $(0.007)$ & $(0.030)$ & $(0.028)$ & $(0.025)$ \\
\hline \multirow[t]{2}{*}{$\Delta B B_{0}^{-}$} & -0.004 & -0.013 & $-0.103^{* * *}$ & 0.011 & -0.078 & $-0.101^{* *}$ & 0.019 & $0.174^{* * *}$ & -0.043 & 0.002 & -0.058 & $-0.125^{* * *}$ \\
\hline & $(0.009)$ & $(0.041)$ & $(0.015)$ & $(0.050)$ & $(0.076)$ & $(0.044)$ & $(0.013)$ & $(0.062)$ & $(0.027)$ & $(0.010)$ & $(0.049)$ & $(0.020)$ \\
\hline \multicolumn{13}{|c|}{ C: Diagnostics } \\
\hline$W_{\mathrm{LR}} H_{0}:$ & 0.570 & 125.35 & 148.49 & 13.400 & 23.240 & 40.850 & 137.74 & 25.940 & 22.500 & 0.050 & 77.670 & 93.580 \\
\hline$\beta^{+}=\beta^{-}$ & {$[0.450]$} & {$[0.000]$} & {$[0.000]$} & {$[0.000]$} & {$[0.000]$} & {$[0.000]$} & {$[0.000]$} & {$[0.000]$} & {$[0.000]$} & {$[0.823]$} & {$[0.000]$} & {$[0.000]$} \\
\hline$W_{\text {ISR }} H_{0}:$ & 3.270 & 0.040 & 90.600 & 0.000 & 1.320 & 24.490 & 3.420 & 8.230 & 57.020 & 13.390 & 0.890 & 48.940 \\
\hline$\pi_{0}^{+}=\pi_{0}^{-}$ & {$[0.071]$} & {$[0.852]$} & {$[0.000]$} & {$[0.958]$} & {$[0.252]$} & {$[0.000]$} & {$[0.065]$} & {$[0.004]$} & {$[0.000]$} & {$[0.000]$} & {$[0.345]$} & {$[0.000]$} \\
\hline$\chi_{k}^{2}[$ Prob $]$ & 6.920 & 0.580 & 6.890 & 0.000 & 0.260 & 6.350 & 0.020 & 0.020 & 0.270 & 9.770 & 0.080 & 7.140 \\
\hline & [0.009] & {$[0.749]$} & {$[0.032]$} & {$[0.974]$} & {$[0.879]$} & {$[0.042]$} & {$[0.891]$} & {$[0.992]$} & {$[0.872]$} & {$[0.002]$} & {$[0.960]$} & {$[0.028]$} \\
\hline Obs. & 5,200 & 2,600 & 5,947 & 780 & 390 & 939 & 1,040 & 520 & 1,252 & 3,380 & 1,690 & 3,756 \\
\hline
\end{tabular}

Notes: The baseline sample is split into before, during and after the GFC for each group. The remainder are similar to Table 3 . 
Table 4

Sub-analysis Pass-Through Results Using $C R$

\begin{tabular}{|c|c|c|c|c|c|c|c|c|c|c|c|c|}
\hline & \multicolumn{3}{|c|}{ Sector } & \multicolumn{3}{|c|}{ Foreign } & \multicolumn{3}{|c|}{ Major } & \multicolumn{3}{|c|}{ Region } \\
\hline Variables & Pre-GFC & GFC & Post-GFC & Pre-GFC & GFC & Post-GFC & Pre-GFC & GFC & Post-GFC & Pre-GFC & GFC & Post-GFC \\
\hline $\begin{array}{l}\text { A: Long ru } \\
L_{C R}^{+}\end{array}$ & $\begin{array}{l}1.010^{* * *} \\
(0.001)\end{array}$ & $\begin{array}{l}1.465^{* * *} \\
(0.015)\end{array}$ & $\begin{array}{l}1.124^{* * *} \\
(0.014)\end{array}$ & $\begin{array}{l}1.036^{* * *} \\
(0.004)\end{array}$ & $\begin{array}{l}1.521^{* * *} \\
(0.053)\end{array}$ & $\begin{array}{l}1.224^{* * *} \\
(0.035)\end{array}$ & $\begin{array}{l}1.007^{* * *} \\
(0.0020\end{array}$ & $\begin{array}{l}1.463^{* * *} \\
(0.023)\end{array}$ & $\begin{array}{l}1.154^{* * *} \\
(0.026)\end{array}$ & $\begin{array}{l}1.014^{* * *} \\
(0.002)\end{array}$ & $\begin{array}{l}1.459^{* * *} \\
(0.022)\end{array}$ & $\begin{array}{l}1.091^{* * *} \\
(0.018)\end{array}$ \\
\hline$L_{C R}^{-}$ & - & $\begin{array}{l}0.885^{* * *} \\
(0.003)\end{array}$ & $\begin{array}{l}0.789^{* * *} \\
(0.003)\end{array}$ & - & $\begin{array}{l}0.875^{* * *} \\
(0.010)\end{array}$ & $\begin{array}{l}0.792^{* * *} \\
(0.006)\end{array}$ & - & $\begin{array}{l}0.887^{* * *} \\
(0.004)\end{array}$ & $\begin{array}{l}0.817^{* * *} \\
(0.005)\end{array}$ & - & $\begin{array}{l}0.884^{* * *} \\
(0.0045)\end{array}$ & $\begin{array}{l}0.776^{* * *} \\
(0.003)\end{array}$ \\
\hline $\mathrm{D}_{(L \mp)}$ & 1.010 & 0.580 & 0.335 & 1.036 & 0.646 & 0.432 & 1.007 & 0.576 & 0.337 & 1.014 & 0.575 & 0.315 \\
\hline$\mu_{i}$ & $\begin{array}{l}3.481^{* * *} \\
(0.473)\end{array}$ & $\begin{array}{l}2.663^{* * *} \\
(0.235)\end{array}$ & $\begin{array}{l}1.460^{* * *} \\
(0.157)\end{array}$ & $\begin{array}{l}3.007^{* *} \\
(1.297)\end{array}$ & $\begin{array}{l}2.228^{* * *} \\
(0.496)\end{array}$ & $\begin{array}{l}1.624^{* * *} \\
(0.163)\end{array}$ & $\begin{array}{l}4.226^{* *} \\
(1.643)\end{array}$ & $\begin{array}{l}3.252^{* * *} \\
(0.954)\end{array}$ & $\begin{array}{l}1.856^{* * *} \\
(0.132)\end{array}$ & $\begin{array}{l}3.364^{* * *} \\
(0.503)\end{array}$ & $\begin{array}{l}2.593^{* * *} \\
(0.200)\end{array}$ & $\begin{array}{l}1.343^{* * *} \\
(0.245)\end{array}$ \\
\hline B: Short ru & & & & & & & & & & & & \\
\hline$\rho_{i}$ & $\begin{array}{l}-0.528^{* * *} \\
(0.072)\end{array}$ & $\begin{array}{l}-0.459^{* * *} \\
(0.040)\end{array}$ & $\begin{array}{l}-0.227^{* * *} \\
(0.024)\end{array}$ & $\begin{array}{l}-0.462^{* *} \\
(0.201)\end{array}$ & $\begin{array}{l}-0.388^{* * *} \\
(0.090)\end{array}$ & $\begin{array}{l}-0.261^{* * *} \\
(0.020)\end{array}$ & $\begin{array}{l}-0.637^{* *} \\
(0.249)\end{array}$ & $\begin{array}{l}-0.557^{* * *} \\
(0.164)\end{array}$ & $\begin{array}{l}-0.289^{* * *} \\
(0.020)\end{array}$ & $\begin{array}{l}-0.511^{* * *} \\
(0.076)\end{array}$ & $\begin{array}{l}-0.447^{* * *} \\
(0.033)\end{array}$ & $\begin{array}{l}-0.208^{* * *} \\
(0.038)\end{array}$ \\
\hline$\Delta C R_{0}^{+}$ & $-0.275^{* * *}$ & $-0.566^{* * *}$ & $-0.261^{* * *}$ & -0.418 & $-0.583^{* * *}$ & $-0.383^{* * *}$ & -0.158 & -0.374 & -0.214 & $-0.284^{* * *}$ & $-0.628^{* * *}$ & $-0.259^{* * *}$ \\
\hline$\Delta C R_{0}^{-}$ & $\begin{array}{l}(0.093) \\
-\end{array}$ & $\begin{array}{l}(0.094) \\
-0.364^{* * *} \\
(0.069)\end{array}$ & $\begin{array}{l}(0.055) \\
-0.201^{* * *} \\
(0.023)\end{array}$ & $\begin{array}{l}(0.260) \\
-\end{array}$ & $\begin{array}{l}(0.206) \\
-0.368^{* * *} \\
(0.086)\end{array}$ & $\begin{array}{l}(0.078) \\
-0.219^{* * *} \\
(0.040)\end{array}$ & $\begin{array}{l}(0.363) \\
-\end{array}$ & $\begin{array}{l}(0.431) \\
-0.293 \\
(0.361)\end{array}$ & $\begin{array}{l}(0.193) \\
-0.230^{* * *} \\
(0.071)\end{array}$ & $\begin{array}{l}(0.086) \\
-\end{array}$ & $\begin{array}{l}(0.063) \\
-0.387^{* * *} \\
(0.033)\end{array}$ & $\begin{array}{l}(0.054) \\
-0.195^{* * *} \\
(0.032)\end{array}$ \\
\hline C: Diagnos & & & & & & & & & & & & \\
\hline $\begin{array}{l}W_{\mathrm{LR}} H_{0}: \\
\beta^{+}=\beta^{-}\end{array}$ & - & $\begin{array}{l}1826.33 \\
{[0.000]}\end{array}$ & $\begin{array}{l}600.40 \\
{[0.000]}\end{array}$ & - & $\begin{array}{l}177.83 \\
{[0.000]}\end{array}$ & $\begin{array}{l}166.86 \\
{[0.000]}\end{array}$ & - & $\begin{array}{l}787.86 \\
{[0.000]}\end{array}$ & $\begin{array}{l}181.64 \\
{[0.000]}\end{array}$ & - & $\begin{array}{l}867.210 \\
{[0.000]}\end{array}$ & $\begin{array}{l}324.15 \\
{[0.000]}\end{array}$ \\
\hline $\begin{array}{l}W_{\mathrm{ISR}} H_{0}: \\
\pi_{0}^{+}=\pi_{0}^{-}\end{array}$ & - & $\begin{array}{l}32.320 \\
{[0.000]}\end{array}$ & $\begin{array}{l}1.410 \\
{[0.234]}\end{array}$ & - & $\begin{array}{l}3.200 \\
{[0.074]}\end{array}$ & $\begin{array}{l}9.570 \\
{[0.002]}\end{array}$ & - & $\begin{array}{l}1.310 \\
{[0.253]}\end{array}$ & $\begin{array}{l}0.000 \\
{[0.944]}\end{array}$ & - & $\begin{array}{l}36.070 \\
{[0.000]}\end{array}$ & $\begin{array}{l}7.400 \\
{[0.007]}\end{array}$ \\
\hline$\chi_{k}^{2}[$ Prob $]$ & $\begin{array}{l}0.440 \\
{[0.507]}\end{array}$ & $\begin{array}{l}2.560 \\
{[0.277]}\end{array}$ & $\begin{array}{l}3.340 \\
{[0.189]}\end{array}$ & $\begin{array}{l}0.420 \\
{[0.518]}\end{array}$ & $\begin{array}{l}1.580 \\
{[0.455]}\end{array}$ & $\begin{array}{l}0.040 \\
{[0.982]}\end{array}$ & $\begin{array}{l}1.510 \\
{[0.219]}\end{array}$ & $\begin{array}{l}1.050 \\
{[0.592]}\end{array}$ & $\begin{array}{l}0.320 \\
{[0.854]}\end{array}$ & $\begin{array}{l}0.540 \\
{[0.463]}\end{array}$ & $\begin{array}{l}1.990 \\
{[0.371]}\end{array}$ & $\begin{array}{l}4.790 \\
{[0.091]}\end{array}$ \\
\hline Obs. & 5,200 & 2,600 & 5,947 & 780 & 390 & 939 & 1,040 & 520 & 1,252 & 3,380 & 1,690 & 3,756 \\
\hline
\end{tabular}

Notes: The baseline sample is split into three subsamples: before, during and after the GFC for each group. The remainder are similar to Table 4 . 
Table 5

The Results of the Optimal NARDL Estimates of the Big-4

\begin{tabular}{|c|c|c|c|c|c|c|c|c|c|c|c|c|c|c|}
\hline \multirow{3}{*}{$\operatorname{NARLD}(p, q)$} & \multicolumn{3}{|c|}{ (a) Long-run asymmetry } & \multicolumn{6}{|c|}{ (b) Short-run asymmetry } & \multicolumn{4}{|c|}{ (c) Diagnostics } & \multirow{3}{*}{$\chi_{S C}^{2}$} \\
\hline & \multirow{2}{*}{$\begin{array}{l}\text { SoA } \\
(\rho)\end{array}$} & \multicolumn{2}{|c|}{ Long-run IRPT } & \multirow{2}{*}{$\begin{array}{c}W_{\mathrm{LR}} \\
H_{\mathrm{o}}: \\
\beta^{+}=\beta^{-}\end{array}$} & \multicolumn{2}{|c|}{ Impact IRPT } & \multirow{2}{*}{$\begin{array}{c}W_{\mathrm{ISR}} H_{\mathrm{o}}: \\
\pi_{0}^{+}=\pi_{0}^{-}\end{array}$} & \multicolumn{2}{|c|}{ Cumulative IRPT } & \multirow{2}{*}{$\begin{array}{c}W_{\mathrm{CSR}} H_{\mathrm{o}}: \\
\sum_{j=0}^{1} \pi_{j}^{+}= \\
\sum_{j=0}^{1} \pi_{j}^{-}\end{array}=$} & \multirow{2}{*}{$\begin{array}{l}\mathrm{Adj} . \\
R^{2}\end{array}$} & \multirow[t]{2}{*}{$t_{\mathrm{BDM}}$} & \multirow[t]{2}{*}{$F_{\text {PSS }}$} & \\
\hline & & $\begin{array}{l}\beta^{+}= \\
-\delta^{+} / \rho\end{array}$ & $\begin{array}{l}\beta^{-}= \\
-\delta^{-} / \rho\end{array}$ & & $\pi_{0}^{+}$ & $\pi_{0}^{-}$ & & $\sum_{j=0}^{1} \pi_{j}^{+}$ & $\sum_{j=0}^{1} \pi_{j}^{-}$ & & & & & \\
\hline \multicolumn{15}{|l|}{ Panel A: BB } \\
\hline $\operatorname{ERMI}(10,3)$ & $\begin{array}{l}-0.064^{* * *} \\
(0.010)\end{array}$ & $\begin{array}{l}0.850^{* * *} \\
(0.040)\end{array}$ & $\begin{array}{l}0.796^{* * *} \\
(0.037)\end{array}$ & $\begin{array}{l}81.808^{* * *} \\
{[0.000]}\end{array}$ & $\begin{array}{l}0.022 \\
(0.046)\end{array}$ & $\begin{array}{l}0.227^{* * *} \\
(0.035)\end{array}$ & - & $0.218^{* * *}$ & $0.450^{* * *}$ & $\begin{array}{l}10.268^{* * *} \\
{[0.000]}\end{array}$ & 0.283 & $\begin{array}{l}-6.188^{* * *} \\
{[0.000]}\end{array}$ & $\begin{array}{l}13.594^{* * *} \\
{[0.000]}\end{array}$ & $\begin{array}{l}1.786 \\
{[0.087]}\end{array}$ \\
\hline $\operatorname{ERM2}(10,3)$ & $\begin{array}{l}-0.078^{* * *} \\
(0.011)\end{array}$ & $\begin{array}{l}0.859^{* * *} \\
(0.039)\end{array}$ & $\begin{array}{l}0.806^{* * *} \\
(0.035)\end{array}$ & $\begin{array}{l}88.704^{* * *} \\
{[0.000]}\end{array}$ & $\begin{array}{l}0.188^{* * *} \\
(0.049)\end{array}$ & $\begin{array}{l}0.310^{* * *} \\
(0.039)\end{array}$ & $\begin{array}{l}3.375^{*} \\
{[0.067]}\end{array}$ & $0.308^{* * *}$ & $0.541^{* * *}$ & $\begin{array}{l}7.303^{* * *} \\
{[0.007]}\end{array}$ & 0.286 & $\begin{array}{l}-6.255^{* * *} \\
{[0.000]}\end{array}$ & $\begin{array}{l}14.375^{* * *} \\
{[0.000]}\end{array}$ & $\begin{array}{l}0.176 \\
{[0.951]}\end{array}$ \\
\hline $\operatorname{ERM3}(10,3)$ & $\begin{array}{l}-0.093^{* * *} \\
(0.012)\end{array}$ & $\begin{array}{l}0.908^{* * *} \\
(0.032)\end{array}$ & $\begin{array}{l}0.826^{* * *} \\
(0.028)\end{array}$ & $\begin{array}{l}180.827^{* * *} \\
{[0.000]}\end{array}$ & $\begin{array}{l}0.241^{* * *} \\
(0.063)\end{array}$ & $\begin{array}{l}0.353^{* * *} \\
(0.047)\end{array}$ & $\begin{array}{l}1.587 \\
{[0.208]}\end{array}$ & $0.241^{* * *}$ & $0.456^{* * *}$ & $\begin{array}{l}6.257^{* *} \\
{[0.013]}\end{array}$ & 0.321 & $\begin{array}{l}-7.472^{* * *} \\
{[0.000]}\end{array}$ & $\begin{array}{l}19.162^{* * *} \\
{[0.000]}\end{array}$ & $\begin{array}{l}2.103 \\
{[0.123]}\end{array}$ \\
\hline $\operatorname{ERM4}(10,3)$ & $\begin{array}{l}-0.107^{* * *} \\
(0.012)\end{array}$ & $\begin{array}{l}0.882^{* * *} \\
(0.029)\end{array}$ & $\begin{array}{l}0.808^{* * *} \\
(0.025)\end{array}$ & $\begin{array}{l}184.261^{* * *} \\
{[0.000]}\end{array}$ & $\begin{array}{l}0.217^{* * *} \\
(0.059)\end{array}$ & $\begin{array}{l}0.228^{* * *} \\
(0.042)\end{array}$ & $\begin{array}{l}0.017 \\
{[0.897]}\end{array}$ & $0.217^{* * *}$ & $0.388^{* * *}$ & $\begin{array}{l}4.182^{* *} \\
{[0.041]}\end{array}$ & 0.287 & $\begin{array}{l}-8.186^{* * *} \\
{[0.000]}\end{array}$ & $\begin{array}{l}23.203^{* * *} \\
{[0.000]}\end{array}$ & $\begin{array}{l}1.729 \\
{[0.189]}\end{array}$ \\
\hline \multicolumn{15}{|l|}{ Panel A: CR } \\
\hline $\operatorname{ERM1}(10,6)$ & $\begin{array}{l}-0.008 \\
(0.007)\end{array}$ & $\begin{array}{l}1.385^{* * *} \\
0.439\end{array}$ & $\begin{array}{l}1.035^{\text {*** }} \\
0.290\end{array}$ & $\begin{array}{l}4.660^{* *} \\
{[0.031]}\end{array}$ & $\begin{array}{l}0.891^{\text {*** }} \\
(0.034)\end{array}$ & $\begin{array}{l}0.675^{* * *} \\
(0.021)\end{array}$ & $\begin{array}{l}32.402^{* * *} \\
{[0.000]}\end{array}$ & $1.845^{* * *}$ & $1.657^{* * *}$ & $\begin{array}{l}5.975^{* *} \\
{[0.015]}\end{array}$ & 0.731 & $\begin{array}{l}-1.094 \\
{[0.274]}\end{array}$ & $\begin{array}{l}1.714 \\
{[0.163]}\end{array}$ & $\begin{array}{l}1.141 \\
{[0.332]}\end{array}$ \\
\hline $\operatorname{ERM2}(10,6)$ & $\begin{array}{l}-0.020^{*} \\
(0.010)\end{array}$ & $\begin{array}{l}1.079^{* * *} \\
(0.129)\end{array}$ & $\begin{array}{l}0.834^{* * *} \\
(0.088)\end{array}$ & $\begin{array}{l}20.429^{* * *} \\
{[0.000]}\end{array}$ & $\begin{array}{l}0.308^{* * *} \\
(0.045)\end{array}$ & $\begin{array}{l}0.133^{* * *} \\
(0.025)\end{array}$ & $\begin{array}{l}11.598^{* * *} \\
{[0.000]}\end{array}$ & $1.701^{* * *}$ & $1.641^{* * *}$ & $\begin{array}{l}0.283 \\
{[0.595]}\end{array}$ & 0.604 & $\begin{array}{l}-1.998 \\
{[0.046]}\end{array}$ & $\begin{array}{l}1.849 \\
{[0.137]}\end{array}$ & $\begin{array}{l}1.931 \\
{[0.129]}\end{array}$ \\
\hline $\operatorname{ERM3}(10,6)$ & $\begin{array}{l}-0.042^{* * *} \\
(0.012)\end{array}$ & $\begin{array}{l}1.157^{* * *} \\
(0.057)\end{array}$ & $\begin{array}{l}0.834^{* * *} \\
(0.035)\end{array}$ & $\begin{array}{l}132.584^{* * *} \\
{[0.000]}\end{array}$ & $\begin{array}{l}0.216^{* * *} \\
(0.046)\end{array}$ & $\begin{array}{l}-0.024 \\
(0.025)\end{array}$ & - & $1.788^{* * *}$ & $1.626^{* * *}$ & $\begin{array}{l}5.393^{* *} \\
{[0.020]}\end{array}$ & 0.756 & $\begin{array}{l}-3.523^{*} \\
{[0.000]}\end{array}$ & $\begin{array}{l}5.399^{* *} \\
{[0.001]}\end{array}$ & $\begin{array}{l}0.816 \\
{[0.634]}\end{array}$ \\
\hline ERM4 $(10,6)$ & $\begin{array}{l}-0.036^{* *} \\
(0.014)\end{array}$ & $\begin{array}{l}1.190^{* * *} \\
(0.090)\end{array}$ & $\begin{array}{l}0.858^{* * *} \\
(0.051)\end{array}$ & $\begin{array}{l}53.455^{* * *} \\
{[0.000]}\end{array}$ & $\begin{array}{l}0.169^{* * *} \\
(0.050)\end{array}$ & $\begin{array}{l}0.003 \\
(0.026) \\
\end{array}$ & - & $2.206^{* * *}$ & $1.974^{* * *}$ & $\begin{array}{l}3.199^{*} \\
{[0.074]}\end{array}$ & 0.682 & $\begin{array}{l}-2.472 \\
{[0.014]}\end{array}$ & $\begin{array}{l}4.969^{* *} \\
{[0.007]}\end{array}$ & $\begin{array}{l}1.041 \\
{[0.374]}\end{array}$ \\
\hline
\end{tabular}

Notes: $W_{\mathrm{LR}}$ is the Wald statistics for the long-run asymmetry. The Wald $F$-statistics for the contemporaneous and cumulative short-run asymmetry are $W_{\text {ISR }}$ and $W_{\mathrm{CSR}}$,

respectively. SoA is the average speed of the adjustment coefficient. Adj. $\mathrm{R}^{2}$ is the values of the adjusted $\mathrm{R}^{2}$ coefficients of the estimations. $t_{\mathrm{BDM}}$ and $F_{\mathrm{PSS}}$ are the $t$ - and $F$ -

statistics of the Bound test for cointegration. The $t_{\mathrm{BDM}}$ by Banerjee et al. (1998) tests the null hypothesis of no cointegration $\mathrm{H}_{0}: \rho_{\mathrm{i}}=0 . F_{\mathrm{PSs}}$ by Pesaran et al. $(2001)$ tests the null $\mathrm{H}_{0}: \rho_{\mathrm{i}}=\delta_{\mathrm{i}}^{+}=\delta_{\mathrm{i}}^{-}=0$, respectively. Critical values for the BDM $t$-test and the PSS $F$-test are, for respectively, $-4.1(1 \%),-3.53(5 \%),-3.21(10 \%)$, and $-6.36(1 \%),-$ $4.85(5 \%),-4.14(10 \%) \cdot \chi_{S C}^{2}$ is the results of the residual serial correlation test. 
(a) Dynamic multipliers for the nexus of the effective mortgage rate-foreign funds rate
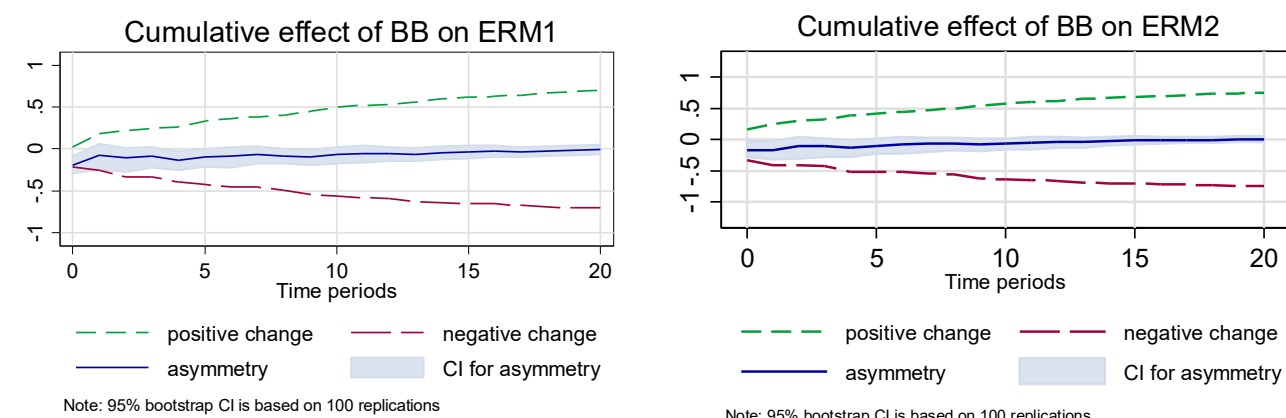

Note: $95 \%$ bootstrap $\mathrm{Cl}$ is based on 100 replications

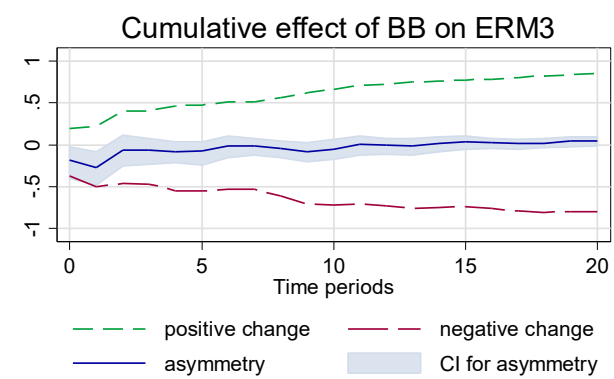

Note: $95 \%$ bootstrap $\mathrm{Cl}$ is based on 100 replications

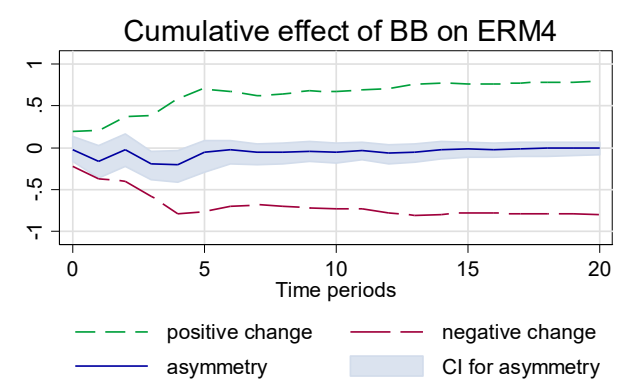

Note: $95 \%$ bootstrap $\mathrm{Cl}$ is based on 100 replications

(b) Dynamic multipliers for the nexus of the effective mortgage rate-cash rate

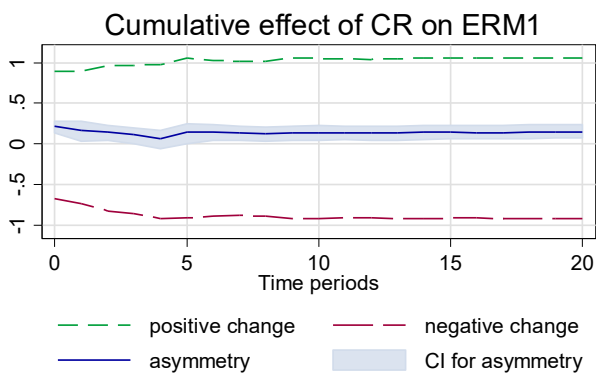

Note: $95 \%$ bootstrap $\mathrm{Cl}$ is based on 100 replication

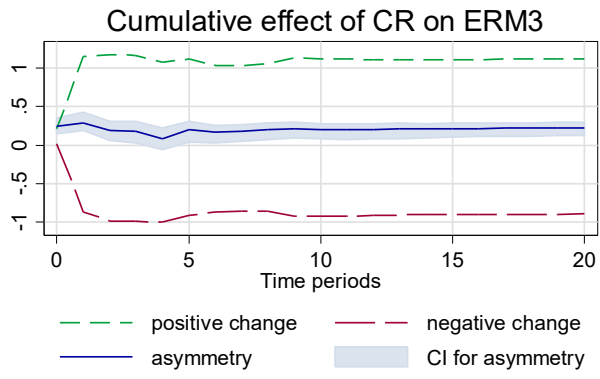

Note: $95 \%$ bootstrap $\mathrm{Cl}$ is based on 100 replication

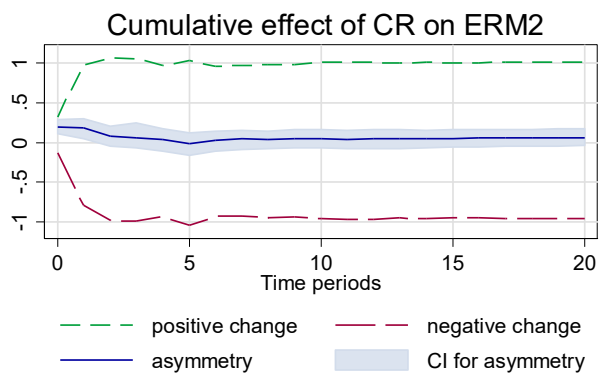

Note: $95 \%$ bootstrap $\mathrm{Cl}$ is based on 100 replication

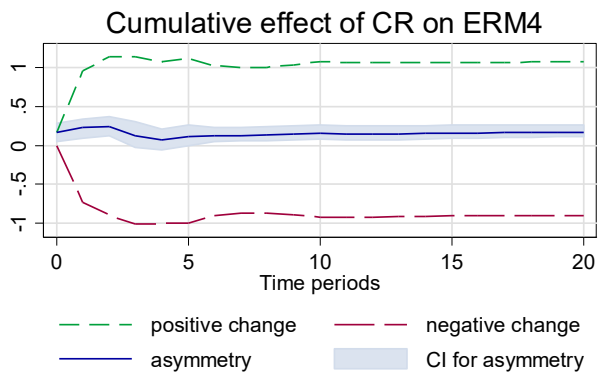

Note: $95 \%$ bootstrap $\mathrm{Cl}$ is based on 100 replication

Figure. 3 Dynamic multipliers for Major-bank mortgage rates. This figure plots the cumulative dynamic multipliers. The green (red) dashed line shows the effect of respectively a 1\% increase (decrease) of the funds rates on the effective mortgage rates in percentage points on the vertical axis. The shared region is its $95 \%$ bootstrap confident interval computed for asymmetry. Weekly intervals are on the horizontal axis. 


\section{Appendix A}

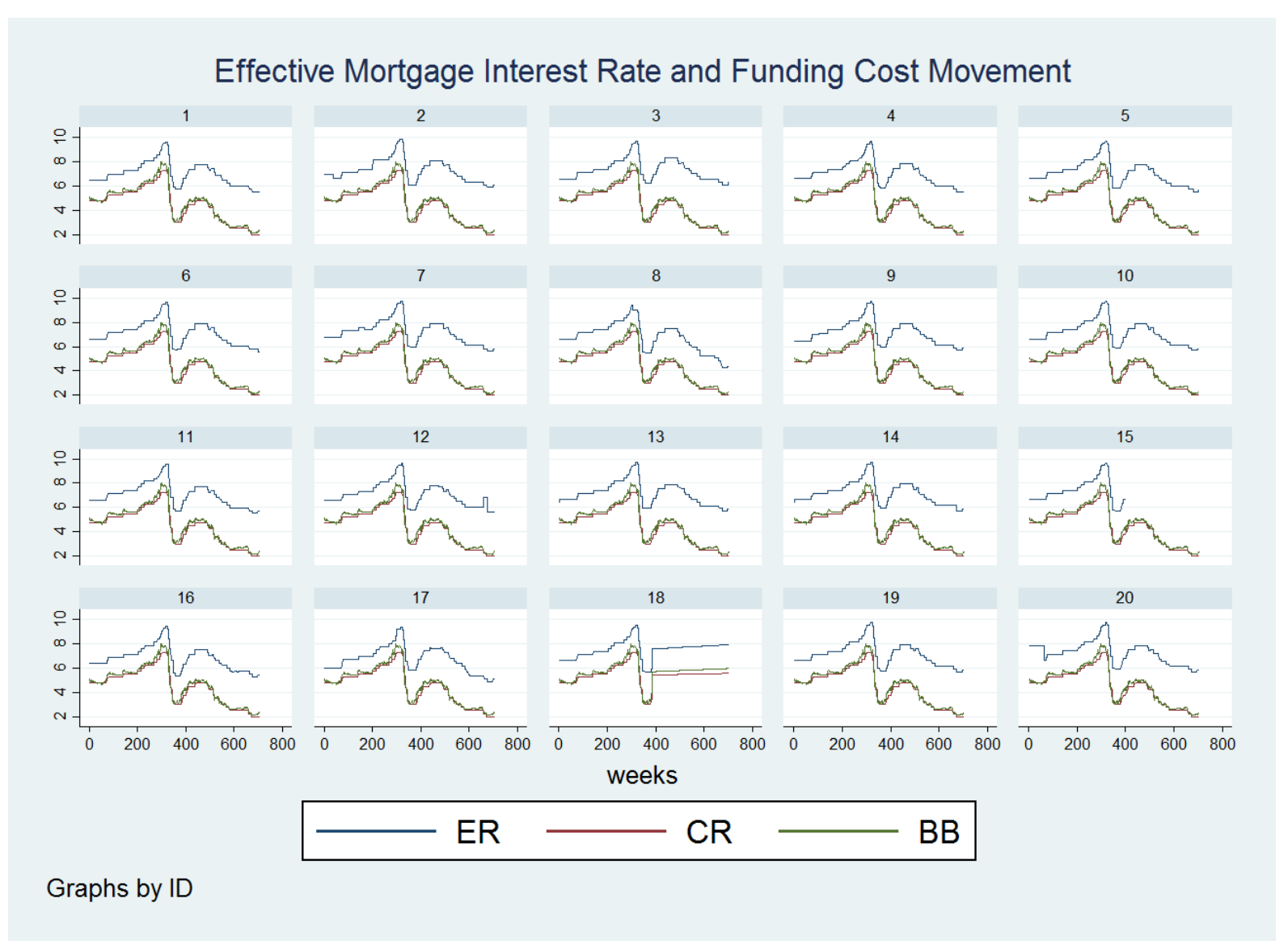

Figure A.1. Plot of the variables

Notes: ER denotes "the effective mortgage interest rate" for each bank. $C R$ and $B B$ are "the cash rate" and "the 3month bank bill swap rate" as two funding cost proxies, domestically and internationally. 
Table A.1

Summary Statistics for Panels/Groups

The mean statistic reveals that the region group is clearly the most competitive in setting effective mortgage rates within Sector, Major, and Foreign groups over time. Foreign has the most expensive charges, except in the pre-crisis period; their rates are higher than those of Sector, and Major. The major lenders set their mortgage rates slightly higher than Sector's. However, the region raises funds at the most expensive rates, both domestic and international. The Bartlett's test is predominantly used to test for equality of more than two means simultaneously, while other tests compare two means only. The aim is to ascertain whether there is a statistically significant difference in the mean values of each of the variables across the three mentioned sub-samples. The Bartlett test results, which are statistically significant at $1 \%$ level, confirm the mean differences among variables within these sub-periods.

\begin{tabular}{|c|c|c|c|c|c|c|c|c|c|}
\hline \multirow[t]{2}{*}{ Variable } & \multicolumn{4}{|c|}{ Mean } & \multicolumn{4}{|c|}{ Std. Dev } & \multirow{2}{*}{$\begin{array}{c}\text { Mean } \\
\text { equality test } \\
\left(\chi^{2}\right)\end{array}$} \\
\hline & Full & $\begin{array}{l}\text { Pre- } \\
\text { GFC }\end{array}$ & GFC & $\begin{array}{l}\text { Post- } \\
\text { GFC }\end{array}$ & Full & $\begin{array}{l}\text { Pre- } \\
\text { GFC }\end{array}$ & GFC & $\begin{array}{l}\text { Post- } \\
\text { GFC }\end{array}$ & \\
\hline \multicolumn{10}{|l|}{ A: Sector } \\
\hline$B B$ & 4.687 & 5.531 & 5.572 & 3.616 & 1.502 & 0.521 & 1.896 & 1.132 & $6.0 \mathrm{e}+03^{* * *}$ \\
\hline$C R$ & 4.450 & 5.362 & 5.289 & 3.454 & 1.432 & 0.489 & 1.750 & 1.079 & $5.8 \mathrm{e}+03^{* * *}$ \\
\hline$E R$ & 7.117 & 7.224 & 7.713 & 6.762 & 0.965 & 0.517 & 1.446 & 0.842 & $4.0 \mathrm{e}+03^{* * *}$ \\
\hline Obs. & 14,120 & 5,220 & 2,620 & 6,280 & 14,120 & 5,220 & 2,620 & 6,280 & \\
\hline \multicolumn{10}{|c|}{ B: Foreign } \\
\hline$B B$ & 4.634 & 5.531 & 5.567 & 3.499 & 1.510 & 0.521 & 1.899 & 1.037 & $914.771^{* * *}$ \\
\hline$C R$ & 4.451 & 5.362 & 5.285 & 3.346 & 1.442 & 0.489 & 1.754 & 0.998 & $885.369^{* * *}$ \\
\hline$E R$ & 7.210 & 7.217 & 7.828 & 6.947 & 0.914 & 0.505 & 1.391 & 0.796 & $587.245^{* * *}$ \\
\hline Obs. & 2,118 & 783 & 393 & 942 & 2,118 & 783 & 393 & 942 & \\
\hline \multicolumn{10}{|l|}{ C: Major } \\
\hline$B B$ & 4.634 & 5.531 & 5.567 & 3.499 & 1.510 & 0.521 & 1.899 & 1.037 & $1.2 \mathrm{e}+03^{* * *}$ \\
\hline$C R$ & 4.451 & 5.362 & 5.285 & 3.346 & 1.442 & 0.489 & 1.754 & 0.997 & $1.2 \mathrm{e}+03^{* * *}$ \\
\hline$E R$ & 7.109 & 7.273 & 7.732 & 6.713 & 0.955 & 0.486 & 1.458 & 0.792 & $925.377^{* * *}$ \\
\hline Obs. & 2,824 & 1,044 & 524 & 1,256 & 2,824 & 1,044 & 524 & 1,256 & \\
\hline \multicolumn{10}{|l|}{ D: Region } \\
\hline$B B$ & 4.715 & 5.531 & 5.574 & 3.679 & 1.497 & 0.521 & 1.895 & 1.175 & $3.9 \mathrm{e}+03^{* * *}$ \\
\hline$C R$ & 4.526 & 5.362 & 5.292 & 3.512 & 1.427 & 0.489 & 1.749 & 1.117 & $3.8 \mathrm{e}+03^{* * *}$ \\
\hline$E R$ & 7.098 & 7.211 & 7.681 & 6.733 & 0.978 & 0.529 & 1.454 & 0.864 & $2.5 \mathrm{e}+03^{* * *}$ \\
\hline Obs. & 9,178 & 3,393 & 1,703 & 4,082 & 9,178 & 3,393 & 1,703 & 4,082 & \\
\hline
\end{tabular}

Notes: $B B$ and $C R$ denote the cash rate and international funding cost. The effective mortgage rate variable is ER for each group. The mean equality, which is chi-square $\left(\chi^{2}\right)$ distributed, is employed to compare the means for pre-GFC, GFC and post-GFC periods. Superscript ${ }^{* * *}$ indicates $1 \%$ level of the significance, while "Obs" represents the total number of observations. 
Table A.2

Testing for the differential effects of $m r$ on $E R$ across sub-periods

\begin{tabular}{|c|c|c|c|c|c|c|c|c|}
\hline \multirow[b]{2}{*}{ Variable } & \multicolumn{2}{|l|}{ Sector } & \multicolumn{2}{|l|}{ Foreign } & \multicolumn{2}{|l|}{ Major } & \multicolumn{2}{|l|}{ Region } \\
\hline & $B B$ & $C R$ & $B B$ & $C R$ & $B B$ & $C R$ & $B B$ & $C R$ \\
\hline \multirow[t]{2}{*}{$m r$} & $0.685^{* * *}$ & $0.702^{* * *}$ & $0.626^{* * *}$ & $0.638^{* * *}$ & $0.675^{* * *}$ & $0.693^{* * *}$ & $0.701^{* * *}$ & $0.720^{* * *}$ \\
\hline & $(0.014)$ & $(0.015)$ & $(0.029)$ & $(0.031)$ & $(0.003)$ & $(0.004)$ & $(0.019)$ & $(0.020)$ \\
\hline \multirow[t]{2}{*}{$D A \_m r$} & $0.131^{* * *}$ & $0.133^{* * *}$ & $0.162^{* * *}$ & $0.162^{* * *}$ & $0.137^{* * *}$ & $0.132^{* * *}$ & $0.121^{* * *}$ & $0.127^{* * *}$ \\
\hline & $(0.009)$ & $(0.008)$ & $(0.015)$ & $(0.015)$ & $(0.006)$ & $(0.007)$ & $(0.013)$ & $(0.011)$ \\
\hline \multirow[t]{2}{*}{$D C \_m r$} & $0.067^{* * *}$ & $0.086^{* * * *}$ & $0.091^{* * *}$ & $0.106^{* * *}$ & $0.065^{* * *}$ & $0.091^{* * *}$ & $0.062^{* * *}$ & $0.079^{* * *}$ \\
\hline & $(0.005)$ & $(0.005)$ & $(0.007)$ & $(0.006)$ & $(0.001)$ & $(0.009)$ & $(0.007)$ & $(0.007)$ \\
\hline \multirow[t]{2}{*}{$\operatorname{ECT}\left(\rho_{\mathrm{i}}\right)$} & $-0.108^{* * *}$ & $-0.147^{* * * *}$ & $-0.096^{* * *}$ & $-0.128^{* * *}$ & $-0.112^{* * *}$ & $-0.141^{* * *}$ & $-0.109^{* * *}$ & $-0.153^{* * *}$ \\
\hline & $(0.005)$ & $(0.012)$ & $(0.004)$ & $(0.009)$ & $(0.008)$ & $(0.033)$ & $(0.007)$ & $(0.017)$ \\
\hline \multirow[t]{2}{*}{$\Delta m r$} & $0.119^{* * *}$ & -0.065 & $0.102^{* * *}$ & $-0.126^{* * *}$ & $0.142^{* *}$ & 0.078 & $0.116^{* * *}$ & $-0.094^{* * *}$ \\
\hline & $(0.021)$ & $(0.044)$ & $(0.011)$ & $(0.012)$ & $(0.063)$ & $(0.208)$ & $(0.027)$ & $(0.026)$ \\
\hline \multirow[t]{2}{*}{ Constant $\left(\mu_{\mathrm{i}}\right)$} & $0.372^{* * *}$ & $0.504^{* * *}$ & $0.366^{* * *}$ & $0.490^{* * *}$ & $0.401^{* * *}$ & $0.513^{* * *}$ & $0.364^{* * *}$ & $0.504^{* * *}$ \\
\hline & $(0.015)$ & $(0.035)$ & $(0.014)$ & $(0.011)$ & $(0.029)$ & $(0.123)$ & $(0.022)$ & $(0.043)$ \\
\hline \multicolumn{9}{|l|}{ Wald test $H_{0}$ : } \\
\hline$D A \_m r=0$ & $199.49^{* * *}$ & $287.67^{* * *}$ & $121.35^{* * *}$ & $112.62^{* * *}$ & $541.62^{* * *}$ & $343.32^{* * *}$ & $86.32^{* * *}$ & $136.28^{* * *}$ \\
\hline$D C \_m r=0$ & $189.75^{* * *}$ & $286.60^{* * *}$ & $187.31^{* * *}$ & $339.95^{* * *}$ & $2209.72^{* * *}$ & $99.82^{* * *}$ & $89.29^{* * *}$ & $147.44^{* * *}$ \\
\hline$D A \_m r=D C \_m r=0$ & $287.28^{* * *}$ & $433.75^{* * *}$ & $232.14^{* * *}$ & $5919.39^{* * *}$ & $4152.73^{* * *}$ & $849.77^{* * *}$ & $144.58^{* * *}$ & $231.82^{* * *}$ \\
\hline Obs. & 13,795 & 13,795 & 2,115 & 2,115 & 2,820 & 2,820 & 8,860 & 8,860 \\
\hline
\end{tabular}

Notes: $m r$ is either the cash rate or the foreign-funds rate. Two dummy variables, DC and DA, are the proxies for the crisis effect.

Asterisks ${ }^{* * *},{ }^{* *},{ }^{*}$ indicate statistical significance at $1 \%, 5 \%$ and $10 \%$ levels. 


\section{Table A.3}

Unit Root Test Results for Panels/Groups

The first category tests the null hypothesis of unit root with common process (Breitung, 2015; Harris \& Tzavalis, 1999; Levin, Lin, \& Chu, 2002).

The second group postulates unit root with individual unit root process (Im, Pesaran, \& Shin, 2003; Maddala \& Wu, 1999), while the third, by Pesaran (2007), tests unit root in the presence of cross-section dependence. These first three classes are categorized into nonstationary tests in the literature owing to their null hypotheses and test procedure. The fourth class testing the null hypothesis of no unit root with common process by Hadri (2000) is conversely the stationary test. The Pesaran (2007) test is a high-powered technique in this analysis because it enables researchers to detect homogeneity $(\mathrm{H} 0)$ or heterogeneity $(\mathrm{HA})$ in various cross-sections in each group.

\begin{tabular}{|c|c|c|c|c|c|c|c|c|c|c|c|c|}
\hline \multirow[t]{2}{*}{ Tests } & \multicolumn{4}{|c|}{$\boldsymbol{B B}$} & \multicolumn{4}{|c|}{$\boldsymbol{C R}$} & \multicolumn{4}{|c|}{$E R$} \\
\hline & Sector & Foreign & Major & Region & Sector & Foreign & Major & Region & Sector & Foreign & Major & Region \\
\hline \multicolumn{13}{|c|}{ A: Null Hypothesis: unit root with common process } \\
\hline $\begin{array}{l}\text { Levin, Lin } \\
\& C h u t^{*}\end{array}$ & $-3.69^{* * * a}$ & $-1.49^{* a}$ & $-1.72^{* * a}$ & $-2.91^{* * * a}$ & $-4.53^{* * * a}$ & $-1.85^{* * * a}$ & $-2.13^{* * * a}$ & $-3.55^{* * * a}$ & $-1.78^{* a}$ & $-18.74^{* * * b}$ & $-20.48^{* * * b}$ & $-1.38^{* a}$ \\
\hline Breitung t-stat. & $-6.33^{* * * b}$ & $-6.10^{* * * b}$ & $-6.10^{* * * b}$ & $-6.46^{* * * b}$ & $-6.61^{* * * b}$ & $-6.21^{* * * b}$ & $-6.21^{* * * b}$ & $-6.84^{* * * b}$ & $-12.60^{* * * b}$ & $-8.68^{* * * b}$ & $-9.08^{* * * b}$ & $-12.10^{* * * \mathrm{~b}}$ \\
\hline $\begin{array}{l}\text { Harris-Tzavalis } \\
\text { rho }\end{array}$ & $0.139^{* * * b}$ & $0.137^{* * * b}$ & $0.13^{* * * b}$ & $0.14^{* * * \mathrm{~b}}$ & $-0.002^{* * * b}$ & $-0.002^{* * * b}$ & $-0.002^{* * * b}$ & $-0.002^{* * * b}$ & $0.005^{* * * \mathrm{~b}}$ & $-0.000^{* * * b}$ & $-0.000^{* * * b}$ & $0.008^{* * * \mathrm{~b}}$ \\
\hline \multicolumn{13}{|c|}{ B: Null Hypothesis: unit root with individual unit root process } \\
\hline $\begin{array}{l}\text { Im,Pesaran \& } \\
\text { Shin W Stat }\end{array}$ & $-27.47^{* * * \mathrm{~b}}$ & $10.91^{* * * \mathrm{~b}}$ & $-12.60^{* * * \mathrm{~b}}$ & $-21.83^{* * * b}$ & $-28.18^{* * * b}$ & $-10.88^{* * * b}$ & $-12.56^{* * * b}$ & $-22.76^{* * * b}$ & $-35.89^{* * * b}$ & $-13.98^{* * * b}$ & $-15.60^{* * * b}$ & $-29.16^{* * * b}$ \\
\hline ADF Fisher $\chi^{2}$ & $4.90^{* * * a}$ & $1.58^{* \mathrm{a}}$ & $1.83^{* * a}$ & $4.32^{* * * a}$ & $3.70^{* * * a}$ & $41.59^{* * * b}$ & $1.30^{* \mathrm{a}}$ & $3.34^{* * * a}$ & $8.39^{* * * a}$ & $3.71^{* * * a}$ & $3.64^{* * * a}$ & $6.60^{* * * a}$ \\
\hline $\begin{array}{l}\text { Pesaran CD } \\
\text { test } \\
\text { C: Null Hypothe }\end{array}$ & s: no unit $r$ & ot with con & mon unit ro & $-3.03^{* * * a}$ & $-3.13^{* * * a}$ & $1.70^{* * * \mathrm{~b}}$ & $1.70^{* * * \mathrm{~b}}$ & $-3.11^{* * * a}$ & $-4.38^{* * * a}$ & $-4.13^{* * * a}$ & $-5.04^{* * * b}$ & $-3.97^{* * * a}$ \\
\hline Hadri Z-stat. & $-0.70^{\mathrm{b}}$ & $0.45^{\mathrm{b}}$ & $0.28^{\mathrm{b}}$ & $-0.46^{\mathrm{b}}$ & $-0.35^{\mathrm{b}}$ & $0.64^{\mathrm{b}}$ & $0.49^{\mathrm{b}}$ & $-0.19^{b}$ & $-2.03^{b}$ & $-0.28^{b}$ & $-0.49^{b}$ & $-1.51^{b}$ \\
\hline $\begin{array}{l}\text { No. of Cross- } \\
\text { sections }\end{array}$ & 19 & 3 & 4 & 12 & 19 & 3 & 4 & 12 & 19 & 3 & 4 & 12 \\
\hline No. of Periods & 706 & 706 & 706 & 706 & 706 & 706 & 706 & 706 & 706 & 706 & 706 & 706 \\
\hline
\end{tabular}

Notes: Superscripts ${ }^{\mathrm{a}}$ and ${ }^{\mathrm{b}}$ denote results obtained at level and first difference, while asterisks ${ }^{* * *},{ }^{* *},{ }^{*}$ indicate statistical significance at $1 \%, 5 \%$ and $10 \%$ levels, respectively. Hadri panel unit root test does not require statistical significance to achieve stationarity, unlike other panel unit root tests. 